\title{
Modeling of Wind Turbines for Power System Studies
}

\author{
TOMÁŠ PETRŮ
}

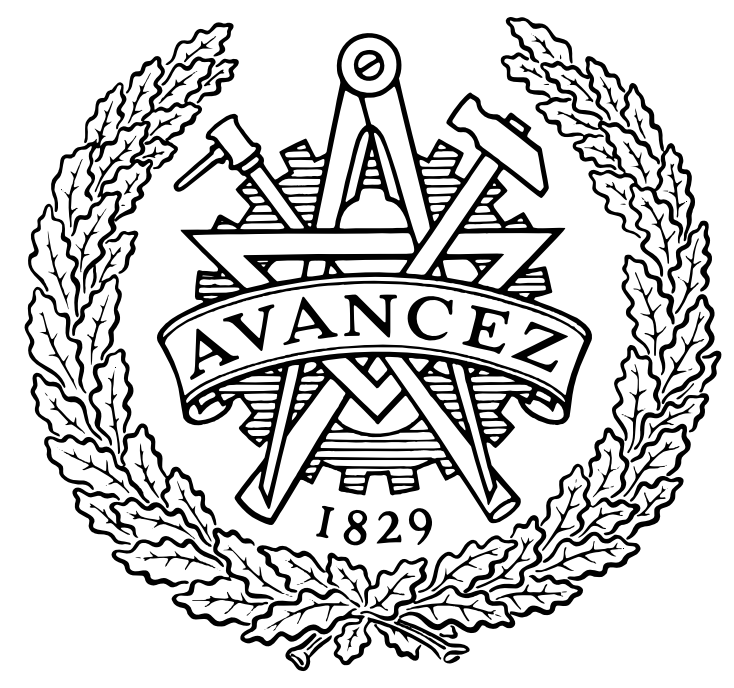

Department of Electric Power Engineering CHALMERS UNIVERSITY OF TECHNOLOGY Göteborg, Sweden 2003 
Modeling of Wind Turbines for Power System Studies TOMÁŚ PETRŮ

ISBN 91-7291-306-1

(C) TOMÁŠ PETRŮ, 2003.

Doktorsavhandlingar vid Chalmers tekniska högskola Ny serie nr 1988

ISSN 0346-718x

Technical Report No. 449

ISSN 1651-498x

Department of Electric Power Engineering

School of Electrical Engineering

Chalmers University of Technology

SE-412 96 Göteborg

Sweden

Telephone + $46(0) 31-7721000$

Chalmers Bibliotek, Reproservice

Göteborg, Sweden 2003 
Modeling of Wind Turbines for Power System Studies

TOMÁŚ PETRÜ

Department of Electric Power Engineering

Chalmers University of Technology

\section{Abstract}

The power quality impact of wind turbines on the electric grid and the response of the wind turbines to faults in the electric grid are investigated in this thesis. A detailed model of a stall-regulated, fixed-speed wind turbine system capable of predicting the flicker impact on the connected grid is presented and compared with field measurements. The responses of fixed-speed and variable-speed wind turbine systems to faults in the electric grid are investigated and compared with field and laboratory measurements. Model structures suitable for grid fault response simulations of the fixed-speed and the variable-speed wind turbine systems are suggested.

In the detailed model of the stall-regulated, fixed-speed system, the wind generation and the aerodynamic conversion are treated in two different ways. A detailed wind field simulation and an aerodynamic conversion based on wing properties are compared with a simplified approach that makes use of a single point wind simulation and the wind turbine power curve. A soft shaft representation is used for the description of the drive train, and the use of different generator model complexities is investigated. Results of the simulations are compared with field measurements and it is found that the measured grid voltage has a significant influence on the obtained results. The short circuit impedance angle of the connected grid has also a significant impact on the accuracy of the results.

It is concluded that the grid fault response of the fixed-speed systems is mainly covered by the drive train and the generator dynamics. The aerodynamic conversion details are of little interest and do not need to be covered by the model structure in this case. Comparisons of measurements and simulations of the system responses to symmetric and asymmetric grid faults show good agreement.

The fault response of variable-speed wind turbine systems is, to a high extent, influenced by the power electronic converters that are utilized in these systems. The response of the systems connected to the grid via a power electronic converter in the stator circuit is not treated in detail since the response is determined mainly by the power electronic converter control algorithm. The variable-speed system with a doubly fed induction generator is dealt with in more detail. It is found that the response of the system to smaller grid faults can be reproduced using the controlled generator description. Field measurements, as well as computer simulations, show poorly damped $50 \mathrm{~Hz}$ oscillations in wind turbine outputs. It is concluded, however, that from the power system point of view this behavior is of negligible interest and the generator control description can be substituted with constant power source. The response of the doubly fed induction generator to more severe grid faults can be covered by the standard induction machine model initiated at a given operating point. Comparisons of measurements and simulations confirm this conclusion. 
Key Words: wind turbine, power quality, flicker, modeling, prediction, measurements, verification, fault response, power system stability, grid simulation 


\section{Acknowledgements}

The Sydkraft Foundation for Research Activities is gratefully acknowledged for the financial support provided throughout the overall research project. I would also like to thank to Dan Andersson and Åke Juntti at Sydkraft AB and Krister Tykeson at Carl Bro AB for talks and feedback.

The financial support for measurement projects and equipment granted by the National Board of Energy Administration is greatly appreciated.

I would like to thank Dr. Niels-Otto Nielssen for allowing measurements on the Jung wind turbine and Tomas Kvist and Torbjörn Karlsson from Kvänum Energi for help with the installation of measurement equipment on the turbine.

Göran Olsson at Vattenfall AB and Christer Liljegren and Lars Barth at GEAB are all acknowledged for help with the measurement projects on Gotland.

Doc. Torbjörn Thiringer has supervised me from the very first day at Chalmers. He has revealed the world of wind energy to me, taught me how to look at things and cope with problems. I am most grateful for all his effort, time, patience and many other things that I may have missed right now. Many thanks.

I greatly appreciate the many fruitful talks and helpful suggestions from my colleagues; Ph.D. candidates Andreas Petersson and Rolf Ottersten.

I have enjoyed the working environment at the Department of Electric Power Engineering and extend my thanks to its entire staff.

The support and encouragement from my relatives and friends in the Czech Republic and Sweden have been crucial for me - thanks for having said what you said and having done what you did.

Last but not least, I can hardly express my gratitude to my girlfriend Iva for her love and unlimited patience. Can I ever compensate you for the time we spent apart? 


\section{LIST OF PUBLICATIONS}

This thesis is based on the work contained in the following papers, referred to in the text:

1. "Wind power stations - the impact on the electric grid, basic configurations and an example of utilisation", Petru, T., The conference on Electric Power Engineering ELEN2000, Prague, Czech Republic, 25.-26.9.2000

2. "Power quality impact of a sea-located hybrid wind park", Thiringer, T., Petru, T., Liljegren, C., IEEE Transactions on Energy Conversion, vol. 16, no. 2, June 2001, p. 123-127

3. "Integration of wind parks - example from Bockstigen", Petru, T., Thiringer, T., Nordic Wind Power Conference NWPC'2000, Trondheim, Norway, 13.14.3. 2000

4. "Active flicker reduction from a sea-based $2.5 \mathrm{MW}$ wind park connected to a weak grid", Petru, T., Thiringer, T., 2000 IEEE Nordic Workshop on Power and Industrial Electronics NORpie/2000, Aalborg, Denmark, 13.-16.6.2000

5. "Measurement and modeling of power quality impact of a stall-regulated wind turbine", Petru, T., Thiringer, T., Electromotion journal, vol. 8, no. 2, April - June 2001, p. 104-110

6. "Flicker contribution from wind turbine installations", Thiringer, T., Petru, T., Lundberg, S., accepted for publication in IEEE transactions on Energy conversion

7. "Electrical Limiting Factors for Wind Energy Installations in Weak Grids", Lundberg, S., Petru, T., Thiringer, T., International Journal of Renewable Energy Engineering, vol. 3, no. 2, August 2001, p. 305-310

8. "Modeling of wind turbines for power system studies", Petru, T., Thiringer, T., IEEE Transactions on Power Systems, vol. 17, no. 4, November 2002, p. $1132-1139$

9. "Grid Disturbance Response of Wind Turbines Equipped with Induction Generator and Doubly-Fed Induction Generator", Thiringer, T., Petersson, A., Petru, T., accepted for IEEE PES Annual Meeting, Toronto, Canada, July 2003 


\section{Contents}

1 Introduction 1

1.1 Wind Energy Development . . . . . . . . . . . . . . . 1

1.2 Power System Worries . . . . . . . . . . . . . . . . . . . . 1

1.3 Modeling of Wind Turbines . . . . . . . . . . . . . . 2

1.4 Aim of the Thesis and the Thesis Layout . . . . . . . . . . . . 3

2 Wind Turbine Systems 5

2.1 Aerodynamic Power Control . . . . . . . . . . . . . . . 5

2.2 Generator Speed Control . . . . . . . . . . . . . . . . . . 6

2.3 Reactive Power Control . . . . . . . . . . . . . . . . . . . . 8

2.4 Common Wind Turbine Systems . . . . . . . . . . . . . 8

3 Power System Demands and Limitations 11

3.1 Power Quality . . . . . . . . . . . . . . . . . . 11

3.2 Power System Stability . . . . . . . . . . . . . . . . . . . . . . 11

3.3 Voltage Dip . . . . . . . . . . . . . . . . . . . . . . . . . . . . . 12

3.4 Wind Turbine Controllability . . . . . . . . . . . . . . . 12

3.5 Comparison of Wind Turbine Systems from a Power System Point of View ....................... 13

3.6 Power System Interests in Wind Turbine Models . . . . . . . . . . . . 13

4 Data Acquisition $\quad 15$

4.1 Measurement Set-up . . . . . . . . . . . . . . . . 15

4.2 Bockstigen-Valar Data Acquisition . . . . . . . . . . . 16

4.3 Alsvik Data Acquisition . . . . . . . . . . . . . . . . 17

4.4 Jung Data Acquisition . . . . . . . . . . . . . . . . . . . . . 18

4.5 Laboratory Measurements . . . . . . . . . . . . . . . 25 
5.1 Steady-State Impact of a Fixed-Speed Wind Turbine . . . . . . . . . 27

5.2 Fault Response of a Fixed-Speed Wind Turbine . . . . . . . . . . . . 29

5.2.1 Three-Phase Induction Machine Model . . . . . . . . . . . . . 29

5.2.2 Two-axis Model of an Induction Machine . . . . . . . . . . . . 31

5.2.3 Higher Order Model of the Induction Machine . . . . . . . . . 31

5.2.4 Experimental Verification ................ 32

5.3 Fault Response of Variable-Speed Wind Turbines . . . . . . . . . . . 32

5.3.1 Variable-Speed System Connected via Power Electronic Converter in the Stator Circuit . . . . . . . . . . . . 35

5.3.2 Variable-Speed System with Doubly-Fed Induction Generator 35

5.3.3 Control of Doubly-Fed Induction Generator . . . . . . . . . 36

5.3.4 Fault Response of Controlled Doubly-Fed Induction Generator 38

5.3.5 Impact of Crow-bar Switching . . . . . . . . . . . . . . . . 41

6 Conclusions and Future Work $\quad 45$

6.1 Steady State Impact . . . . . . . . . . . . . . . . . . 45

6.2 Fault Response . . . . . . . . . . . . . . . . . . . 46

6.3 Future Work . . . . . . . . . . . . . . . . . . . . 47 


\section{Chapter 1}

\section{Introduction}

\subsection{Wind Energy Development}

Mankind has used wind as a source of energy for thousands of years. It was one of the most utilized sources of energy together with hydro power during the seventeenth and eighteenth centuries [1]. By the end of the nineteenth century the first experiments were carried out on the use of windmills for generating electricity. Thereafter, there was a long period of a low interest in the use of wind power. The international oil crisis in 1972 initiated a restart of the utilization of renewable resources on a large scale, wind power, among others.

Currently, wind power is a fully established branch on the electricity market and it is treated accordingly. Energy production is not the only criterion to be considered when installing new wind turbines; cost efficiency, the impact on the environment and the impact on the electric grid are some of important issues of significant interest when making decisions about new wind turbine installations.

Political support for and public interest in renewable energy has caused a massive increase in wind power utilization and improvement of wind turbine technology is a natural consequence. Presently, wind power meets about $2 \%$ of the total electricity demand in Europe [2], i.e. more than $23000 \mathrm{MW}$ of which about $5800 \mathrm{MW}$ was installed in the last year (2002). According to [2], this development is going to continue in coming years.

\subsection{Power System Worries}

The position of wind turbine installations in the power system structure is changing, hand in hand, with the massive increase in installed wind power capacity. In the 80's and 90's wind turbines were treated as small local power sources that were of negligible importance from a power system point of view. The stochastic nature of wind raised a certain reluctance on the part of utility companies to introducing a power source with unknown behavior, which was said "to be a potential troublemaker". The utility companies have been responsible for maintaining grid power quality and 
there was, thus, a need to model and predict the impact of wind turbines on power quality.

Today, the impact of wind installations on power quality is less of a problem for several reasons. Measurements on wind turbines and analyzes of the mutual impact of turbines and the grid have been made, and based on the findings, standards for connecting wind turbines to the grid have been defined. Wind turbine technology has been developed accordingly in order to meet the new standards. Moreover, turbines, today, are usually installed in clusters rather than one by one and this often implies that the transmission capacity of the utilized electric grid is properly adjusted, which often means that the relative power quality impact of the total wind installation is lowered.

The massive increase in installed wind power and the enormous plans for future use of wind power raise another worry from the power system side. Wind power cannot be treated as an "unimportant" power source any more, since it represents a higher fraction of the total power system installed capacity. The impact of wind turbines on power system stability is often mentioned and, consequently, there is great interest in modeling and predicting wind turbine response to the transient behavior of the power system.

\subsection{Modeling of Wind Turbines}

Modeling wind turbines for predicting of their power quality impact is reported in the literature. Models of wind turbines of varying complexity are presented. Electrical engineers, for example, tend to simplify the aerodynamic and mechanic parts of the system and usually stress generator description. In contrast, mechanical engineers often overlook generator performance details. Some reported models seem to be over-parameterized, which obstructs their implementation because the parameters for the detailed description are not generally available.

Simplified aerodynamic modeling of wind turbines has been presented in [3], [4]. The main idea in these articles is to adjust wind speed data at one point (hub level) by the use of various filters in order to represent the interaction of turbine blades with wind speed distribution over the rotor swept area. The resulting wind data are then applied to the static power curve, $C_{p}(\lambda)$, in order to determine the driving torque. In contrast to this, an advanced approach to aerodynamic modeling, that uses a professional software package has been presented in [5].

The complexity of the reported drive-train models varies considerably, however, rather simplified descriptions that often incorporate a soft shaft representation dominate completely in the literature. The soft shaft representation is presented, for example, in [6]. A very complex drive-train model representation that might suffer from the unavailability of system parameters is presented in [7] and [8].

A wide range of generator model complexities can be found in the literature. In [4] no dynamic generator model is used at all while [9] makes use of a generator model with neglected stator and rotor dynamics. [10] utilizes a generator model with 
neglected stator dynamics and in [11] a generator model with incorporated stator and rotor dynamics is employed. A detailed analysis of the induction machine with a particular interest in low frequency disturbances can be found in [12].

Verifications of models with practical measurements on wind turbines are rarely reported in the literature. A comparison of simulations and measurements of wind turbine responses to grid disturbances have not been found at all by the author. A published comparison between measured and simulated impact of wind turbines during normal operation, namely the comparison of flicker impact, has been found in [5]. Good agreement is reported there, however, only a single result for one wind speed is presented.

The prediction of voltage fluctuations caused by variable-speed turbines is not of interest from the point of view of power quality, since variable-speed wind turbines have rather low flicker emission as reported in [13]. However, the prediction of voltage fluctuations due to fixed-speed turbines is very important, since this is often one of the restrictions that sets installation limits for these turbines [14].

The impact of wind turbines on power system stability is also dealt with in the literature. The work presented in [6] describes a model of a grid-connected wind generator designed for predicting both, steady-state operation impact as well as the response to grid faults. However, verification of the simulation results against field measurements is lacking. An evaluation of the fault response of fixed-speed wind turbines and of variable-speed wind turbines equipped with doubly-fed induction generators is analyzed in [15]. In this paper, conclusions and recommendations regarding an appropriate integration of the wind turbines into the power system are based on performed simulations.

\subsection{Aim of the Thesis and the Thesis Layout}

Based on the need for knowledge of the interaction between the grid and wind turbine installations, a project was designed with the following aims:

- to obtain and analyze measurements on the most common wind turbine systems used today and those planned for the near future

- based on the findings, decide which grid integration aspects are prone to restrict the use of wind turbine systems

- to develop wind turbine models that can predict the identified wind turbine critical behavior for the corresponding wind turbine types

- to verify the simulation results against measurements to the highest possible degree

- to simplify the developed model structures to a level that still describes the phenomenon of interest and at the same time can be implemented in grid simulation programmes 
The thesis is composed of a collection of published journal and conference papers that are introduced and referred to in the body of the thesis. The body of the thesis is divided into the following chapters:

Chapter 2 gives a brief overview of the common wind turbine systems used today (2003).

Chapter 3 summarizes power system limitations and demands that are often discussed in relation to wind power.

Chapter 4 describes the data acquisition set-up used for measurements and introduces the measurement sites.

Chapter 5 presents the suggested model structures and shows some of the achieved results.

Chapter 6 contains conclusions and options for future research. 


\section{Chapter 2}

\section{Wind Turbine Systems}

A basic overview of common wind turbine systems currently in use is given in this chapter. Means of aerodynamic power control are shortly summarized, as well as wind turbine speed control and the control of reactive power exchanged with the connected grid.

\subsection{Aerodynamic Power Control}

Aerodynamic power control is based on the aerodynamic properties of the wind turbine rotor blade. There are two forces that act on the rotor disc; edge force that builds up shaft torque (orthogonal to the free wind direction) and thrust that imposes unwanted load on the turbine (parallel to the free wind direction). Both of these forces depend on the aerodynamic profile of the blade, on the wind speed, $W$, and on the angle of attack, $\alpha$. Fig. 2.1 shows the discussed terms.

However, rather than using the angle of attack, the tip speed ratio, i.e. the ratio between blade tip speed and incoming free wind speed, $\lambda=\frac{\Omega R}{W S}$, is often used. The relation between the aerodynamic efficiency of a wind turbine, $C_{p}$, and the tip speed ratio is a commonly used description for the conversion of wind speed to shaft torque.

Aerodynamic power control for a given wind speed can be achieved either by means of wind turbine rotor speed control or by pitching the blades. Fig. 2.2 presents the resulting power versus wind speed characteristics of these control strategies.

The traditional wind turbine used to be a fixed-speed turbine with fixed pitch, i.e. a stall-regulated, fixed-speed wind turbine. This wind turbine has blades firmly attached to the hub and no generator speed control. Active-stall controlled systems, also called combi-stall controlled systems, are of the same type, however, they allow the blades to be pitched. This pitching is done within a rather narrow range, a range from 0 to 4 degrees in Fig. 2.2 corresponds to the active-stall control range for the blade profile used here. The third aerodynamic control strategy for wind turbines is pitch control. The blades are pitched in a broad range, from 0 to about 30 degrees in Fig. 2.2. The thick line in Fig. 2.2 represents a variable-speed, pitch-regulated 


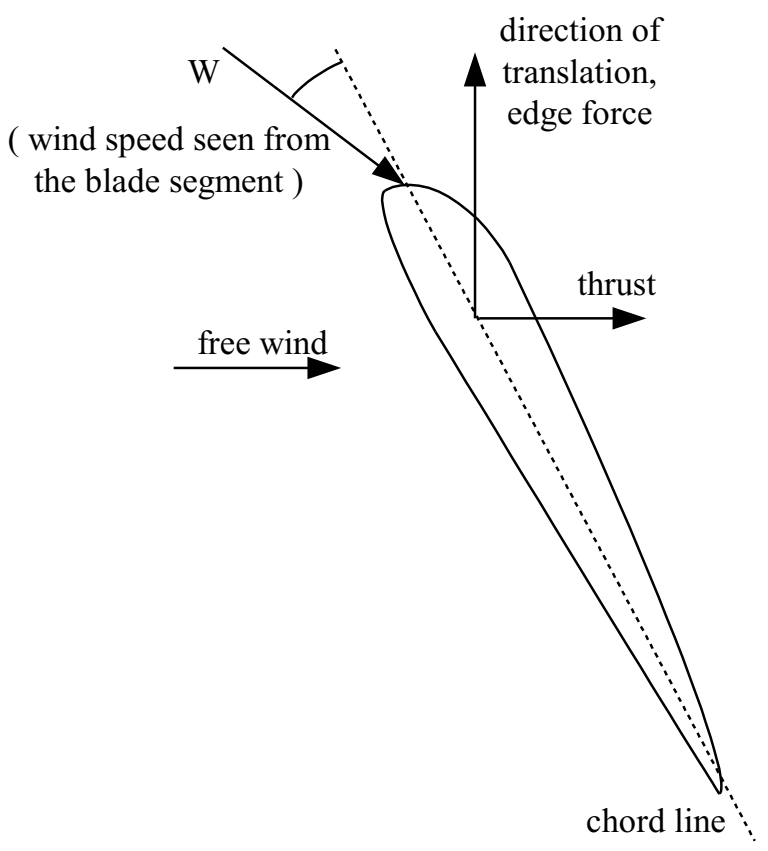

Figure 2.1: Wing profile

system in which turbine speed and the blade pitch angle are controlled according to Fig. 2.3 and Fig. 2.4, respectively.

\subsection{Generator Speed Control}

In the previous section, the potential of using variable rotor speed for adjusting aerodynamic power was mentioned. This, however, is not the main reason for using turbine speed control. Instead, it is the fact that the variable speed operation gives the potential to reduce mechanical stresses on drive-train components by means of shaft torque control. Incoming power variations are absorbed by changes in the rotor speed and the shaft torque is smoother, which also gives smoother electric output power.

Fixed-speed systems, i.e. systems without active speed control, typically utilize an induction generator directly connected to the grid. Variable-speed systems make use of either induction generators or synchronous generators. Both of these systems require a power electronic converter to obtain torque and speed control. Induction generators with a wound rotor are mainly used. The use of a wound rotor allows a power electronic converter to be connected to the rotor circuit via slip rings. The advantage of this is that variable speed control is obtained using a power electronic converter designed for lower power than nominal power, typically about $20-30 \%$, [16]. The power electronic converter and the slip rings can be avoided completely in systems with a variable rotor resistance connected to the rotor. In this type of system, externally switched resistances are added to the rotor circuit and rotate together with the rotor of the generator. The speed range of such a system is, however, limited by the maximum power that can be dissipated in the rotor resistances and 


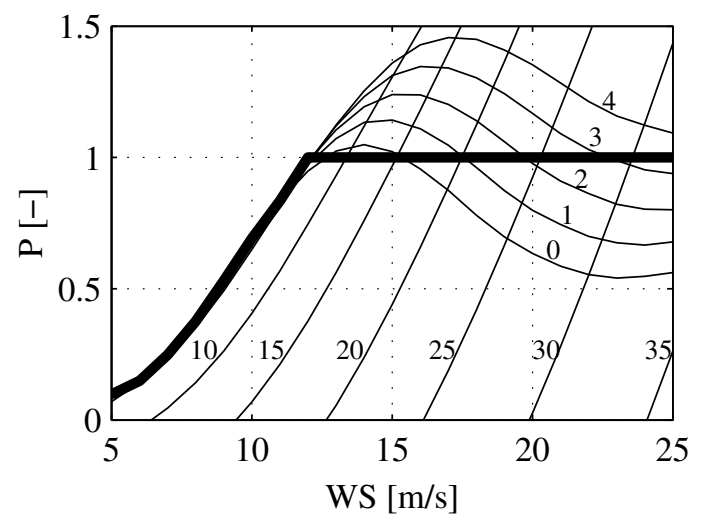

Figure 2.2: Aerodynamic power control, thin lines represent fixed-speed system with different but fixed pitch angles, thick line represents pitch-regulated system

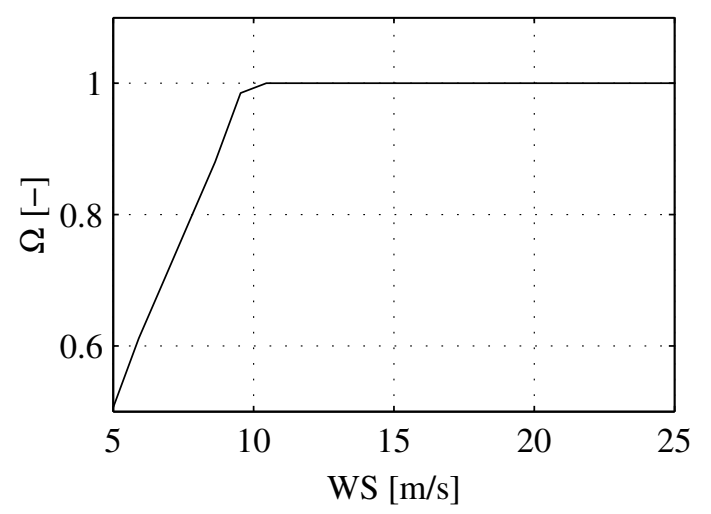

Figure 2.3: Turbine speed as a function of wind speed for a variable-speed, pitchregulated wind turbine

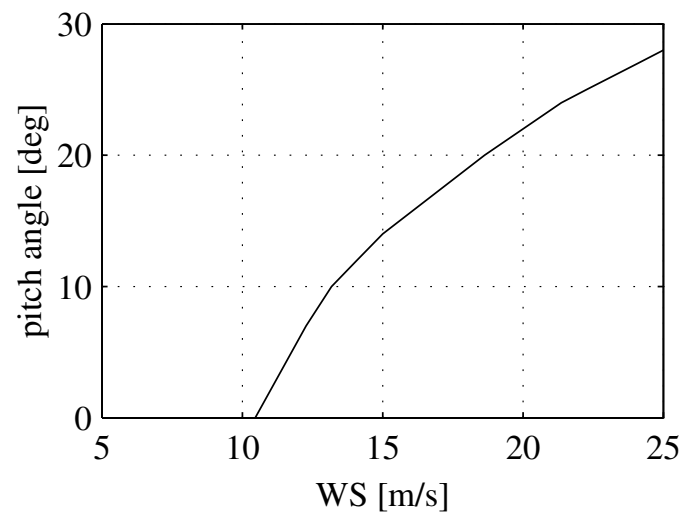

Figure 2.4: Blade pitch angle as a function of wind speed for a variable-speed, pitch-regulated wind turbine 


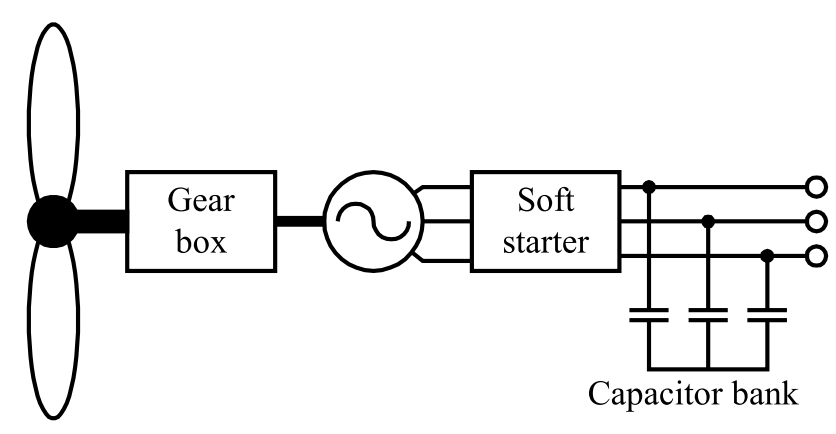

Figure 2.5: Fixed-speed system with stall or active-stall control

is narrower than the speed range of the system with the power electronic converter in the rotor circuit, a span of about $10 \%$ is, for example, used for a $660 \mathrm{~kW}$ turbine [17]. The power losses that occur in the controlled rotor resistances also make this system less favourable.

\subsection{Reactive Power Control}

The reactive power control of a wind turbine is determined by the generator system in use. The most simple system with an induction generator directly connected to the grid utilizes a capacitor bank typically designed to compensate for generator no-load reactive power consumption. The additional reactive power consumed when the generator is loaded must be taken from the connected grid.

Systems with power electronic converters offer much more powerful reactive power control. Provided that the rating of the converter allows it, they can fully compensate the generator for its reactive power demand, i.e. maintain power factor one at the generator output at any load if so desired. They can also be used for voltage level control in the grid like a static voltage compensator. It is worth mentioning that with appropriate control of reactive power, the voltage variations due to uneven active power production can be counteracted and, in this way, flicker emission to the grid can be reduced, as shown in Publication 2, Publication 3 and Publication 4.

\subsection{Common Wind Turbine Systems}

A fixed-speed wind turbine system with either stall or active-stall control is a commonly used system today (2003). It is popular due to its simplicity and robustness. Active-stall control is mainly employed in bigger units with rated power roughly over 1MW. A gear box and a reactive power compensating capacitor bank are standard components in this wind turbine system. Fig. 2.5 shows the principal layout of such a system. There is also a fixed-speed, pitch-regulated system but it is not common system. This system has some less favourable features like considerable gear box wear-out and high variations in output power. Pitch control is, today, almost exclusively used in combination with the variable-speed operation. 


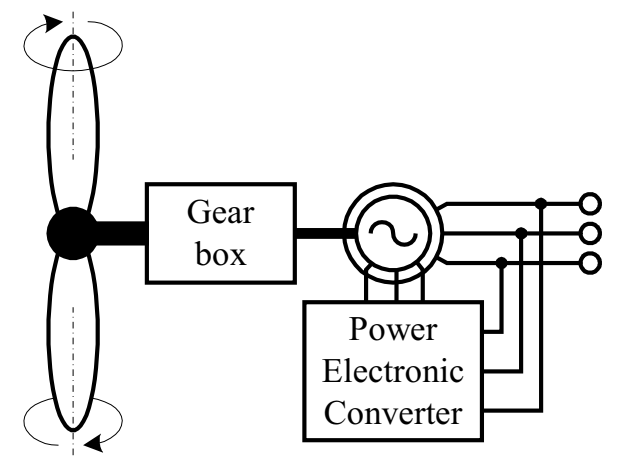

Figure 2.6: Variable-speed, pitch-regulated system with doubly-fed induction generator

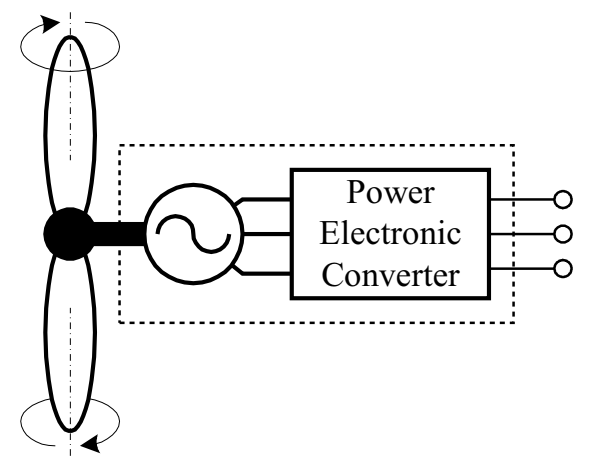

Figure 2.7: Variable-speed, pitch-regulated system with synchronous generator

A variable-speed, pitch-regulated system with a doubly-fed induction generator is currently very popular and is likely to be one of the dominant wind turbine systems, at least in the near future. Fig. 2.6 shows principal layout of such a system.

A variable-speed, pitch-regulated system with a full power electronic converter and a multipole synchronous generator is also a commonly used system today. This configuration is particularly interesting as it allows for a design without a gear box, [18]. Fig. 2.7 shows principal layout of this system. There are also few examples of using an induction generator with a gearbox and a full power electronic converter but they are uncommon. 


\section{Chapter 3}

\section{Power System Demands and Limitations}

Installation of any equipment to the power system is subject to installation recommendations. Installation requirements for wind turbines in Sweden are specified in [19], a document fairly similar to the international standard [20]. [19] deals with the impact of a wind installation on the electric grid and, in principal, prescribes power quality limits that may not be exceeded by the operation of the wind turbine installation.

As the amount of installed wind power increases, it becomes more important to guarantee that the stability of the power system is not endangered by a large-scale wind power installation. Issues of concern are small-signal stability, voltage stability and the fact that voltage dips may lead to disconnection of wind power production.

\subsection{Power Quality}

The power quality limitations that are often linked with wind turbine installations are the impact on the grid voltage in the long-term as well as in short-term time frame, i.e. steady-state voltage level impact and dynamic voltage variations impact, commonly known as a flicker. Voltage transients due to wind turbine switching and harmonic distortion to the grid are other issues of interest. More discussion on this topic can be found in [21].

\subsection{Power System Stability}

Power system stability is an obvious concern, as wind turbine installations contribute more and more to total generated power in the power system. It may be of operational interest to keep a wind turbine connected to the grid even during a grid fault situation. A minor fault in the electric grid should not give rise to any unnecessary massive disconnection of a large number of wind turbines, as might 


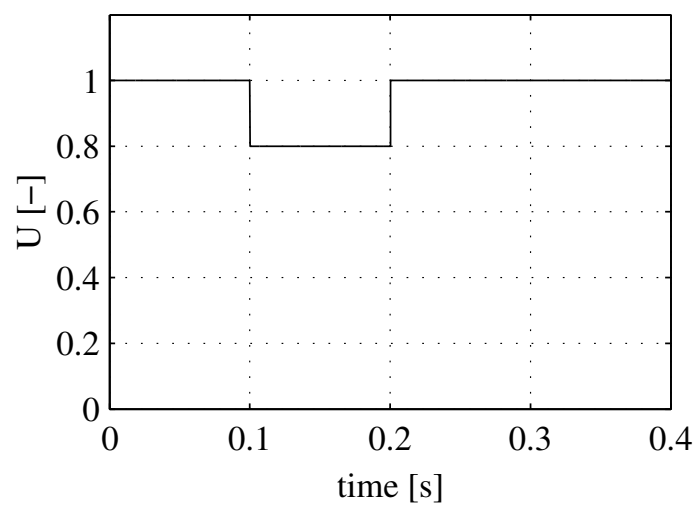

Figure 3.1: Voltage dip

be the case if the protection strategy has not been well thought out in advance. Behavior that leads to a sudden loss of power generating capacity could actually cause more severe consequences compared to the "standard" response of the power system to the initial grid fault. The loss of the power production from a wind installation would need to be instantly compensated for from another source in order to maintain a balanced operation of the power system, to prevent interruptions on the customer end and to avoid transmission line overload. Not satisfying a power system balanced operation could lead to transmission lines tripping. This would result in interruptions on the customer end that might be costly or, in an extreme case, in a power system black-out.

Wind turbine manufacturers / owners, in contrast, are interested in grid fault for the opposite reason; to protect the wind turbine. The wind turbine is protected by devices that are set up to disconnect the turbine from the electric grid if grid conditions become non-standard.

\subsection{Voltage Dip}

Since the term voltage dip is frequently used in this thesis a brief definition is mentioned here in order to prevent any confusion or misunderstanding. Fig. 3.1 shows a simple voltage dip down to $80 \%$ of the nominal voltage with a duration of $0.1 \mathrm{~s}$.

The terminology used in this thesis refers to this dip as $80 \%$ voltage dip, i.e. it is the remaining grid voltage that is used for the dip designation. This terminology is adopted from [22].

\subsection{Wind Turbine Controllability}

In order to find a balance between the power system and wind turbine requirements, there must be a certain level of control over the wind turbine. Wind turbine control, however, significantly depends on the wind turbine type used. 
The fixed-speed, stall-regulated system does not offer means to control wind turbine response to a grid fault. The response of this system is fully determined by the induction generator response. Disconnecting the wind turbine from the grid may very likely be the only means of protecting the wind turbine from a possible failure.

Variable-speed, pitch-regulated systems connected to the grid through power electronic converters can basically provide a fully controlled response to a grid fault. The fault current can be limited by the power electronic converter and the pitch regulation can keep the turbine speed within the requested limits.

Variable-speed, pitch-regulated systems equipped with doubly-fed induction generators can handle a response to a less severe grid fault in the same way as a system with a full power converter. However, more severe grid faults may give rise to a wind turbine response that cannot be completely handled by the generator system. In such a case, the rotor of the generator needs to be short-circuited in order to protect both, the power electronic converter and the generator, from overvoltages and overcurrents. The system behaves in this case like a squirrel cage induction generator and needs to be disconnected as soon as possible. This is the state of the current situation. It is worth noting that wind turbine manufacturers invest a lot of effort into reducing this problem today.

\subsection{Comparison of Wind Turbine Systems from a Power System Point of View}

A summary of the interaction of the most common types of wind turbines with the power system is provided in Table. 3.1. Statements regarding power quality impact are based partly on results published in the attached publications and partly on a literature study, e.g. [13], [14], [21], [23].

\subsection{Power System Interests in Wind Turbine Models}

There is an interest in predicting wind turbine power quality impact on the electric grid and in predicting the wind turbine response to grid faults. Since wind turbines were not a common device in electric grids in the past, their representation is not usually available in grid simulation software tool libraries. However, present situation and estimates for a huge expansion of wind power call for development of appropriate wind turbine models.

Predicting steady-state voltage impact on the electric grid only requires knowledge of the output active and reactive power of the generator. Such information should be readily available for any type of wind turbine at a known wind speed.

Predicting the impact on dynamic voltage variations is mainly of interest for fixedspeed systems since the variable-speed systems are unlikely to cause any consider- 
Table 3.1: Interaction of wind turbines with power system

\begin{tabular}{|l|c|c|c|}
\hline & FSS - SR / ASR & VSS - PR, DFIG & VSS - PR, full power PEC \\
\hline $\mathrm{U}$ & uncontrolled & controlled & controlled \\
\hline $\mathrm{P}_{\mathrm{st}}$ & mediocre & low & low \\
\hline THD & - & mediocre / high & mediocre / high \\
\hline Start up & mediocre & low & low \\
\hline Fault response & uncontrolled & semi-controlled & controlled \\
\hline
\end{tabular}

The following abbreviations are used in the Table:

U steady-state voltage impact

$\mathrm{P}_{\text {st }} \quad$ dynamic voltage variations impact (flicker)

THD harmonic distortion to the grid

Start up voltage disturbances during start up

SR stall-regulated turbine

ASR active-stall regulated turbine

PR pitch-regulated turbine

FSS fixed-speed system

VSS variable-speed system

DFIG doubly-fed induction generator

PEC power electronic converter

able disturbance of this sort, [13]. The model structure of a fixed-speed system is presented later in this thesis.

Harmonic pollution to the grid from systems with power electronic converters can be effectively reduced by the use of proper harmonic filters. Details of the aerodynamic conversion, drive train dynamics and the generator behavior are of minor importance when predicting harmonic pollution to the grid.

Wind turbine response to grid faults is mainly covered by the electric equipment of a wind turbine. In this thesis, only short-term grid faults are considered. This means that during a grid fault, the driving torque of the generator is considered to be constant. Proper generator representation is a crucial requirement if generator response to a grid fault is to be modeled. The use of power electronic converters in wind turbine systems strongly affects the fault response of the wind turbine. It is mainly the control of the converters that determines wind turbine behavior during such an event. Since the control strategy is usually a trade secret, it is only the manufacturer that can provide an accurate wind turbine model for a specific turbine. This issue is dealt with later in this thesis. 


\section{Chapter 4}

\section{Data Acquisition}

Data acquisition on three wind turbine sites as well as laboratory measurements have been conducted throughout the research project. The purpose was to analyze the power quality impact of the different wind turbine systems and to acquire data to be used for verifying the derived wind turbine models. The grid fault response of the wind turbine systems was also recorded in few cases. In order to obtain responses to various grid faults, experiments were performed and data acquired in the laboratory on a $15 \mathrm{~kW}$ squirrel cage induction machine and on a $3 \mathrm{~kW}$ wound rotor induction machine. This chapter presents the layout of the measurement set-up and introduces the measurement sites and laboratory equipment.

\subsection{Measurement Set-up}

The basic layout of the data acquisition system used for measurements is presented in Fig. 4.1

The measuring box transforms the measured electric quantities, currents and voltages, into a range applicable to the data acquisition card. Another important func-

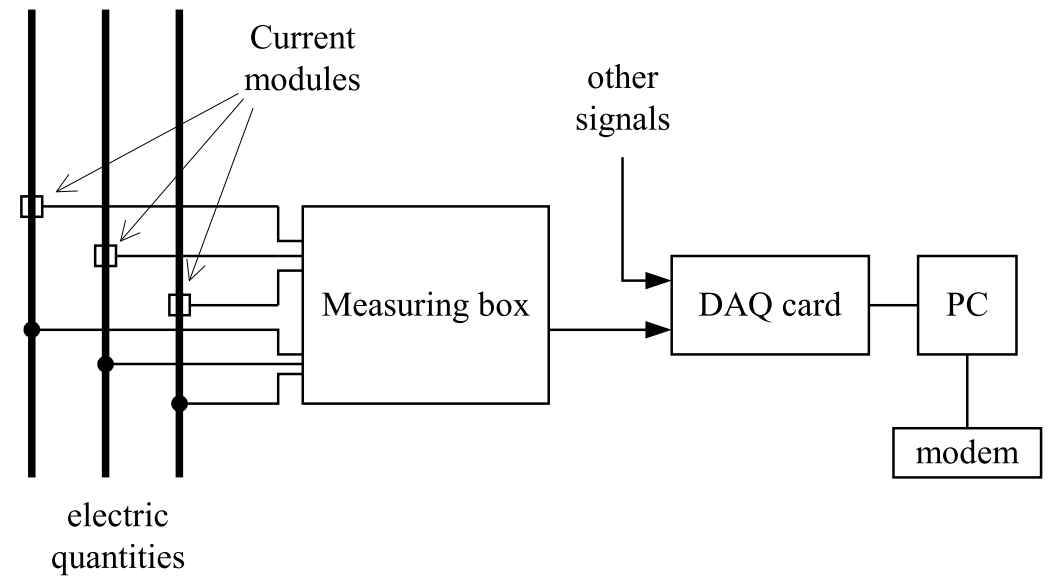

Figure 4.1: DAQ set-up layout 


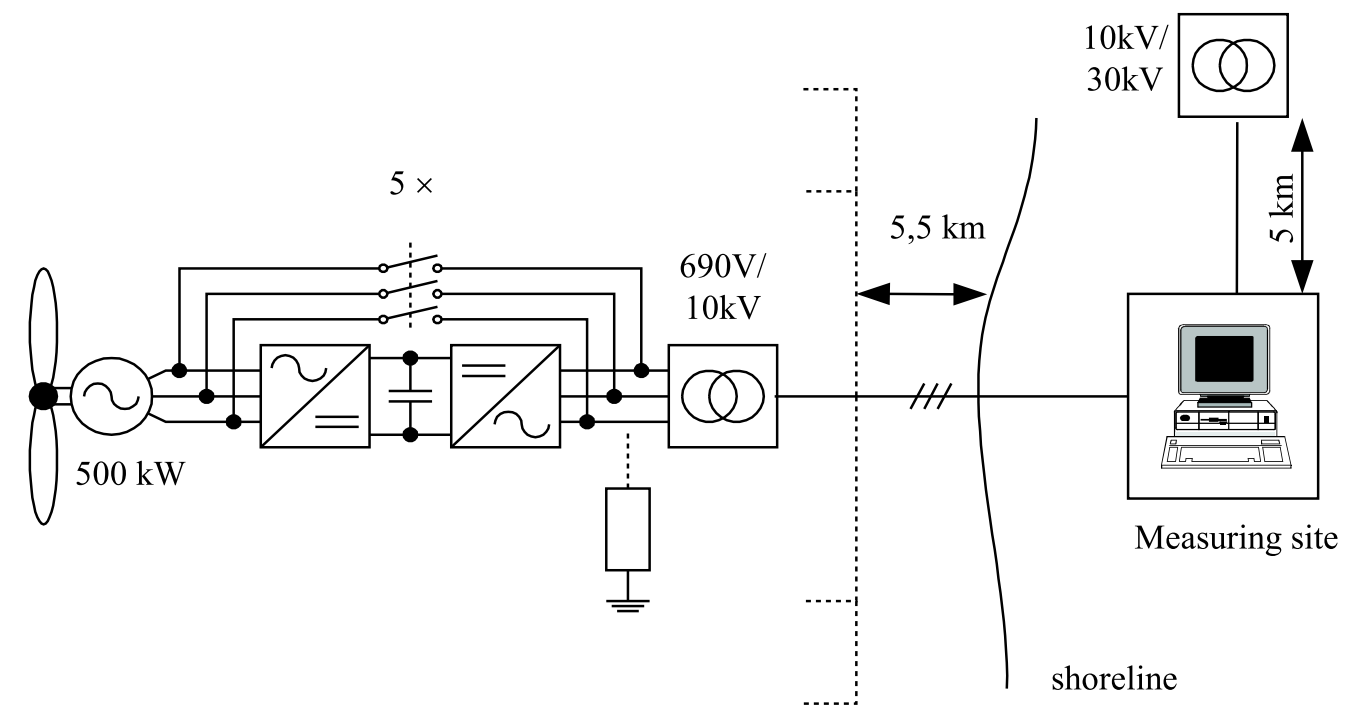

Figure 4.2: Electric sketch of the Bockstigen-Valar wind farm

tion of the measuring box is to protect both the system undergoing the test as well as the measuring equipment, so that they cannot endanger each other. The data acquisition card is the interface between the measuring box and the computer. Its function is to prevent unwanted frequency content in the inputs by using anti-alias filtering, to simultaneously sample all the inputs, the sample and hold function, and finally to transform the signals from the analog to digital domain. The computer controls the adjustment of the data acquisition card, its filtering and sampling frequency, and stores the acquired data. If possible, a modem is a very valuable part of the system. The potential for remote checking and controlling the system is an important function in data acquisition at remote sites. Moreover, an electric supply to the whole DAQ system via an uninterruptible power supply is necessary when response to grid faults is to be recorded.

\subsection{Bockstigen-Valar Data Acquisition}

A project concerned with evaluating the power quality impact of a wind farm connected to a weak grid was conducted at the first Swedish off-shore wind farm situated close to the south-west coast of the island of Gotland in the Baltic sea. There, five semi-variable, stall-regulated wind turbines, each rated at $500 \mathrm{~kW}$, are connected to the grid with a short circuit ratio, the ratio between the short circuit capacity of the grid and the rated power of the wind power installation, of about 7.5. This value is considerably lower than what is common in Sweden. Figure 4.2 shows the wind farm configuration.

The wind turbines operate at a variable speed during low wind speed periods when the output power per turbine is up to about $100 \mathrm{~kW}$. When the wind speed is higher, the turbines run at a fixed speed. PECs are used, in this case, to minimize power quality impact on the grid. A description of control objectives, data acquisition and main results together with conclusions can be found in Publication 2, Publication 3 


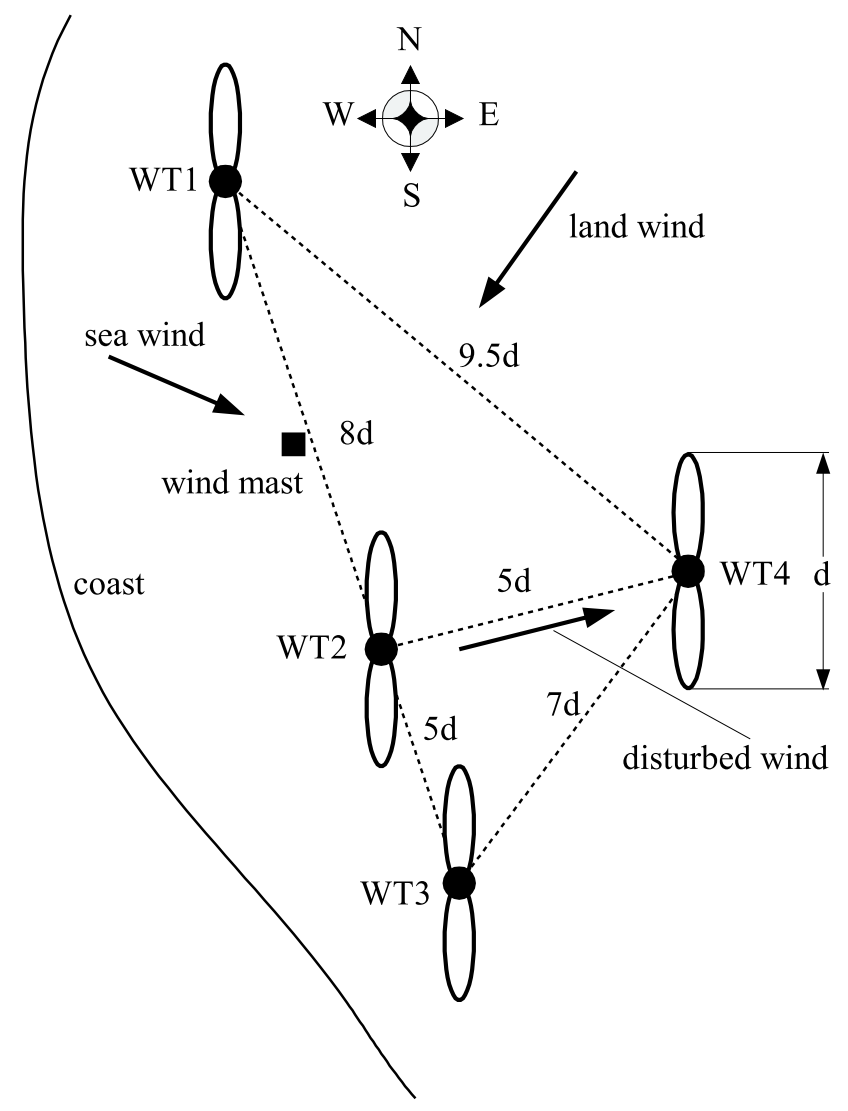

Figure 4.3: Alsvik wind farm

and Publication 4.

A general conclusion is that the Bockstigen wind park utilizes the existing line capacity to the maximum without violating stated power quality limits.

\subsection{Alsvik Data Acquisition}

A wind farm consisting of four $180 \mathrm{~kW}$ stall-regulated, fixed-speed turbines located on the island of Gotland was chosen for data collection to verify the stall-regulated, fixed-speed system model. Figure 4.3 presents the Alsvik wind farm layout, where the term d designates rotor diameter.

The location on the coast offers the potential for comparing the impact of different wind conditions, less disturbed sea winds and more disturbed land winds, on the outputs from the turbines. Moreover, the geometry of the wind farm, the placement of the turbines and the distances between them, further extends the range of possible case studies since different wake operations can be evaluated.

Each turbine is equipped with an induction generator and a capacitor bank. All turbines share one common $400 \mathrm{~V} / 10 \mathrm{kV}$ transformer. Figure 4.4 shows the electrical connection layout. 


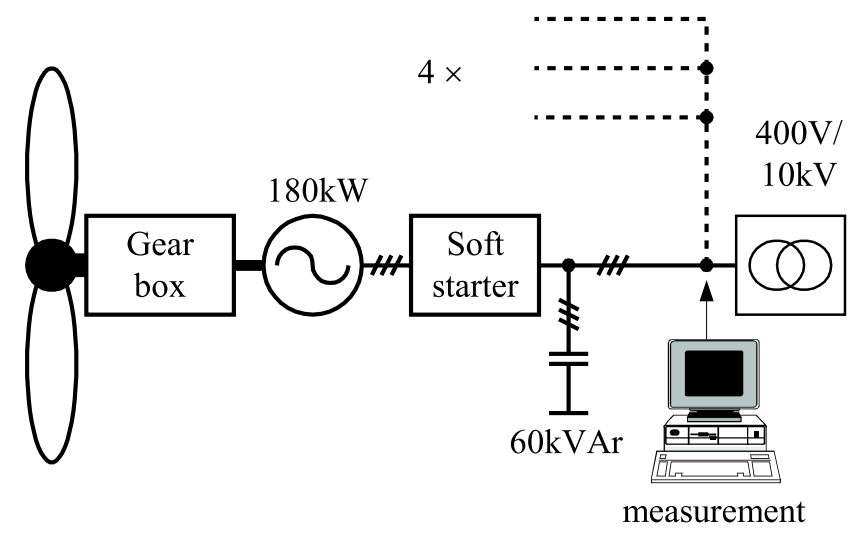

Figure 4.4: Alsvik - grid connection and location of the DAQ system

The data acquisition system collected grid voltages and currents from turbines WT2, WT3 and WT4; turbine WT1 broke down before the start of the test program. The wind direction and three wind speed signals, at hub level and at the upper and lower margins of the rotor swept area, were collected too. The sampling rate used during data acquisition was an important option and had to be chosen with respect to the purpose of the measurements.

The main objective, here, was to evaluate the impact of wind turbines on dynamic voltage variations. Frequency components up to about $30 \mathrm{~Hz}$ are of interest when evaluating $\mathrm{P}_{\mathrm{st}}$ values. According to [20] the bandwidth of the data acquisition system should be about $400 \mathrm{~Hz}$ when the dynamic voltage variations are to be evaluated. This requires a sampling frequency of about $1200 \mathrm{~Hz}$. Since the storing capacity of the DAQ system was not unlimited, an acceptable lower frequency had to be chosen after verifying the results with the suggested sampling speed.

Based on the results obtained from the Bockstigen-Valar data acquisition, Publication 2, and on a comparison with a calibrated measurement system Siemens oscillostore P 513 , a sampling rate of $256 \mathrm{~Hz}$ was chosen. Figure 4.5 shows the comparison of data acquired with the oscillostore and the data collected with the data acquisition system and, consequently, evaluated according to the standards [24]. As can be seen, the results obtained with the data acquisition system follow the values given by the oscillostore very well.

\subsection{Jung Data Acquisition}

Data acquisition on a variable-speed, pitch-regulated wind turbine equipped with doubly-fed induction generator has been carried out on the Vestas V52-850kW wind turbine [25] located close to Jung in the Västra Götaland region in Sweden. Apart from grid voltages and currents even currents on both sides of the rotor power electronic converter along with the pitch angle signal were collected. Fig. 4.6 shows an overview of the data acquisition set up at Jung.

During the whole period of data acquisition, no violation of power quality limits prescribed in [19] was detected. The steady-state voltage level, $P_{s t}$ index and current 


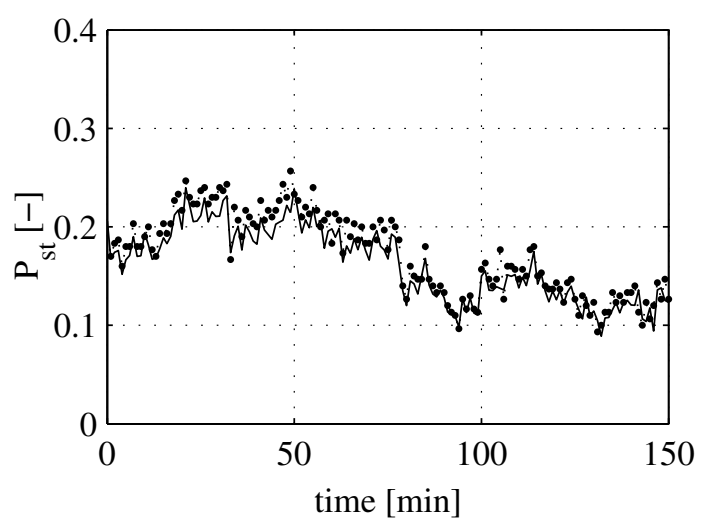

Figure 4.5: $\mathrm{P}_{\mathrm{st}}$ comparison : solid line - data acquisition system, dots - oscillostore

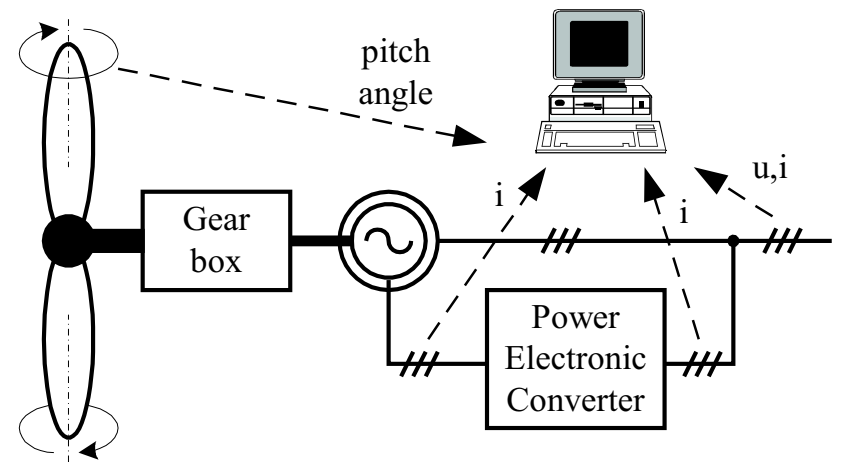

Figure 4.6: Data acquisition set up at Jung 

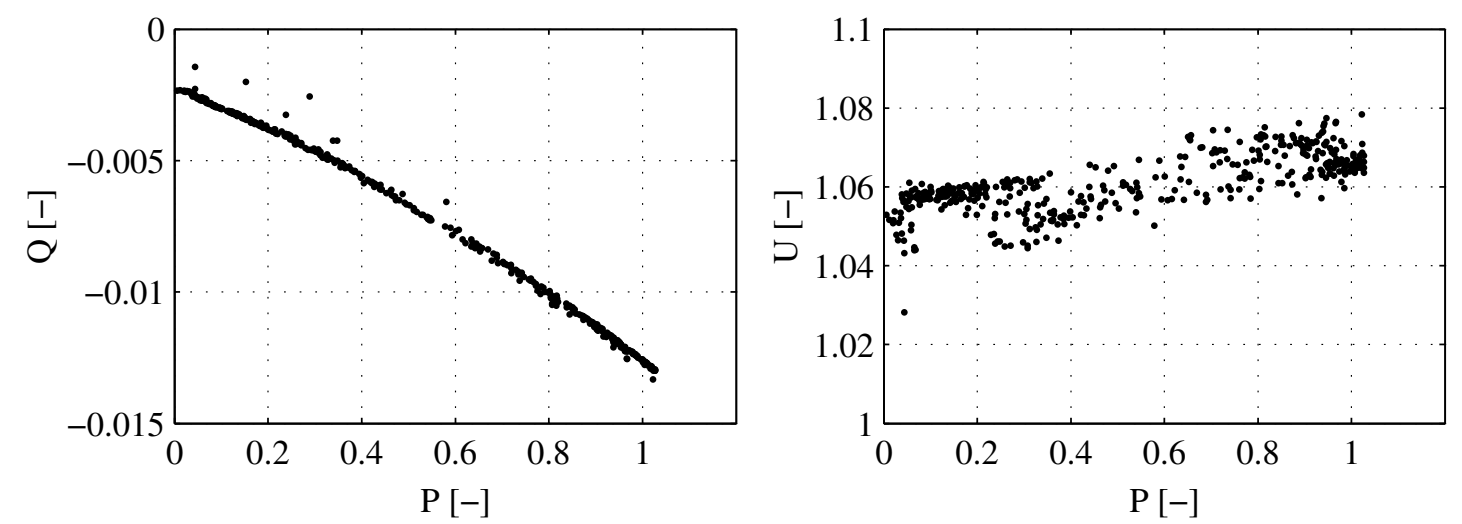

Figure 4.7: Measured reactive power (left) and measured voltage level (right) as functions of active power at Jung
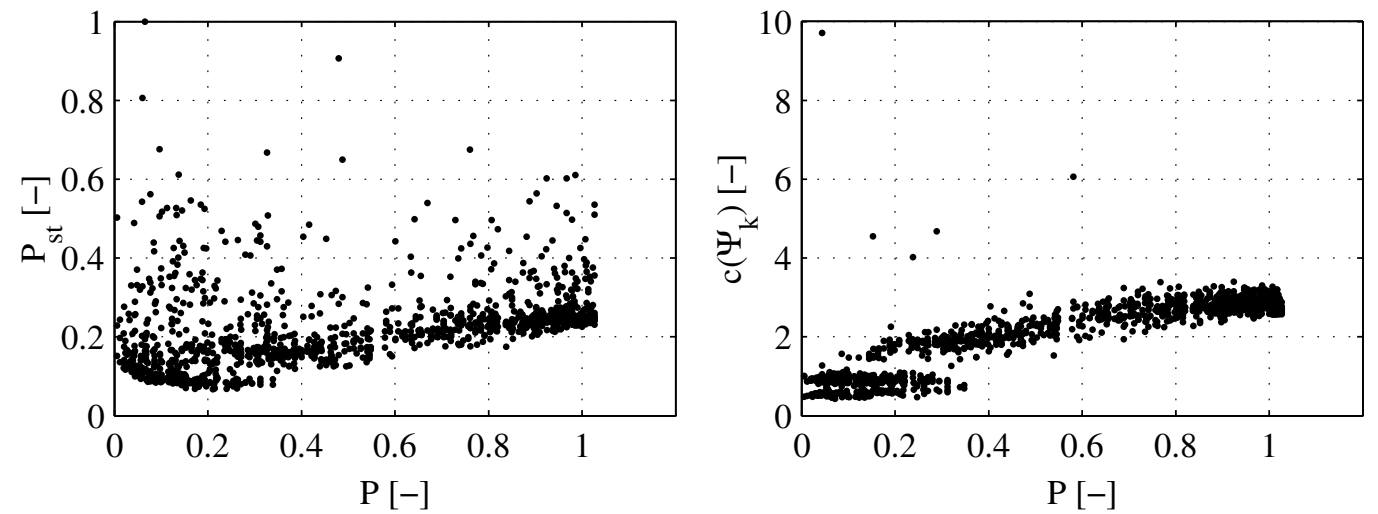

Figure 4.8: $P_{s t}$ in the grid (left) and turbine flicker coefficient (right) as functions of active power at Jung

and voltage total harmonics distortion were within prescribed limits. Steady-state characteristics of the turbine gathered in June 2002 are presented here. Fig. 4.7 shows the reactive power and the voltage level in the grid plotted as functions of the produced active power, each dot represents three minutes' average value. Fig. 4.8 shows one minute $P_{s t}$ values evaluated for measured grid voltage according to [20] and the turbine flicker coefficient $c\left(\Psi_{k}\right)$, also defined by [20], here determined for the turbine impact on a fictive grid with a grid angle of 30 degrees. Fig. 4.9 presents voltage and current harmonics distortion evaluated according to [26].

The currents drawn from the grid during the start up of the turbine were far from the generator nominal current and the $P_{s t}$ value identified during start up reached a value of about 0.5 as can be seen in Fig. 4.8. Start up of the turbine during a high wind speed period is plotted in Fig. 4.10 and Fig. 4.11. Active and reactive power, pitch angle and generator speed are presented. Since the generator speed is derived from measured rotor currents, it is first determined when the rotor circuit is closed, as can be seen in Fig. 4.11 (about time $=60 \mathrm{~s}$ ). It can also be seen that the controlled start of the turbine does not introduce any significant power peak.

A few occasions of minor grid fault, i.e. symmetric and asymmetric voltage dips in a range about $80 \%-90 \%$, were also recorded but none of them caused the turbine 

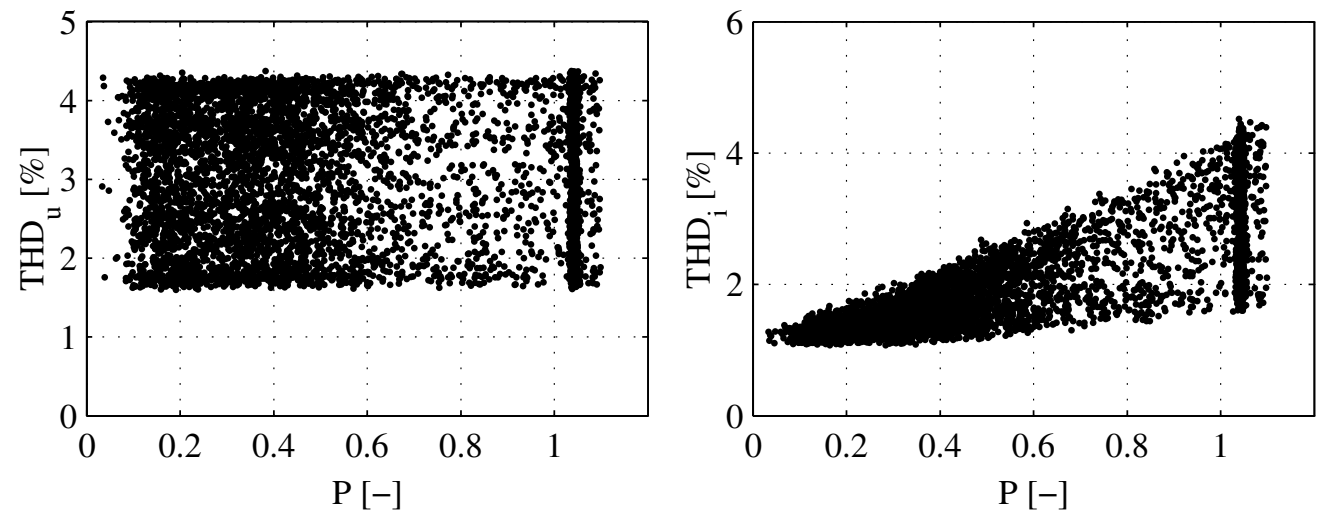

Figure 4.9: Total harmonics distortion in voltage (left) and current (right) as functions of active power at Jung
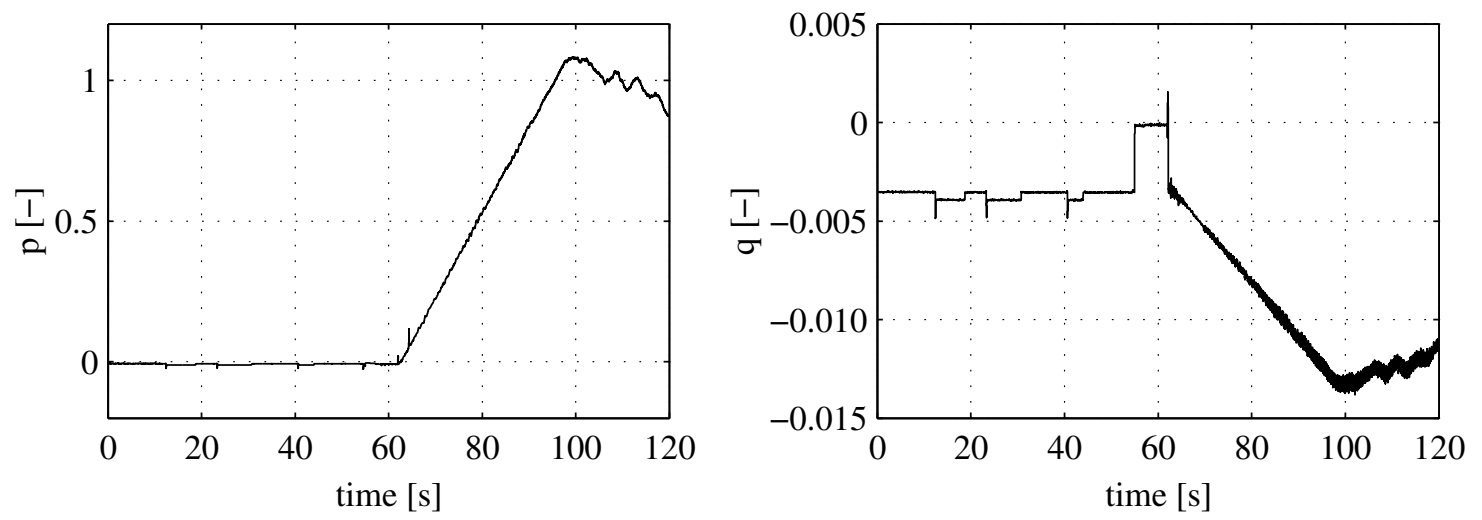

Figure 4.10: Wind turbine start at Jung, active (left) and reactive (right) power
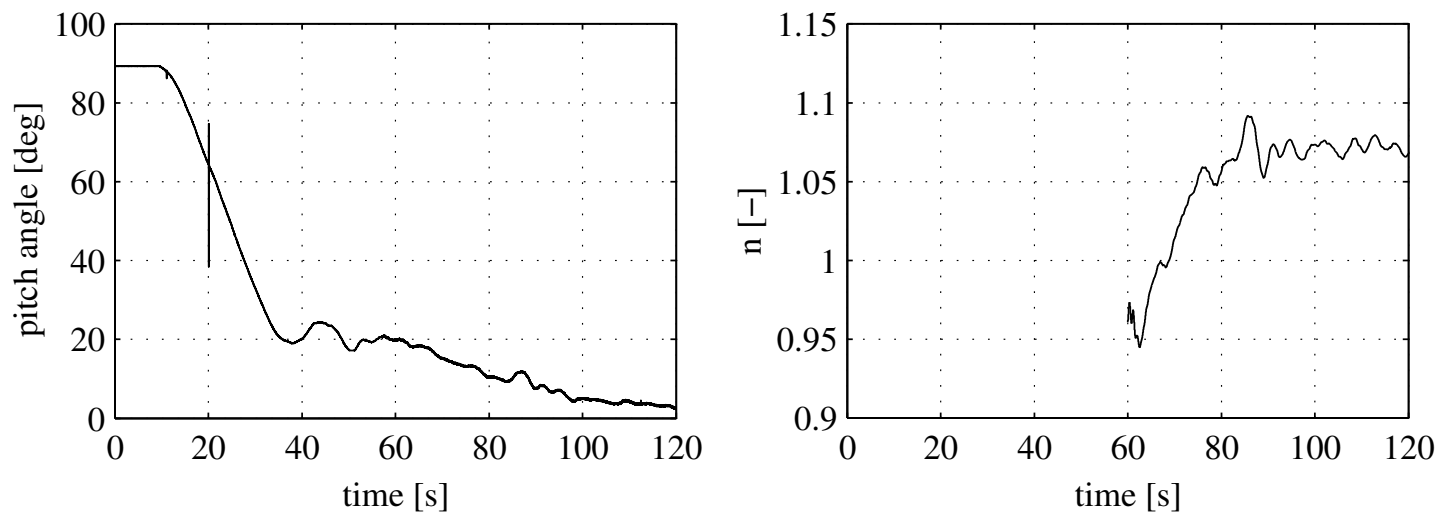

Figure 4.11: Wind turbine start at Jung, pitch angle (left) and generator speed (right) 

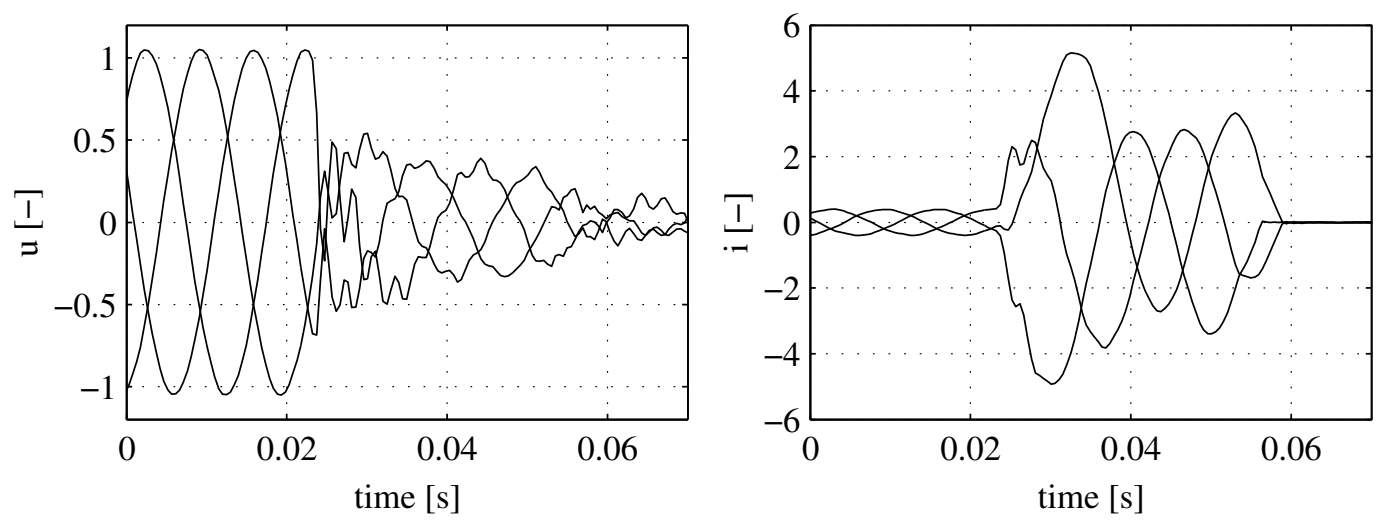

Figure 4.12: Total short-circuit in the near grid at Jung, grid voltages (left) and turbine currents (right)
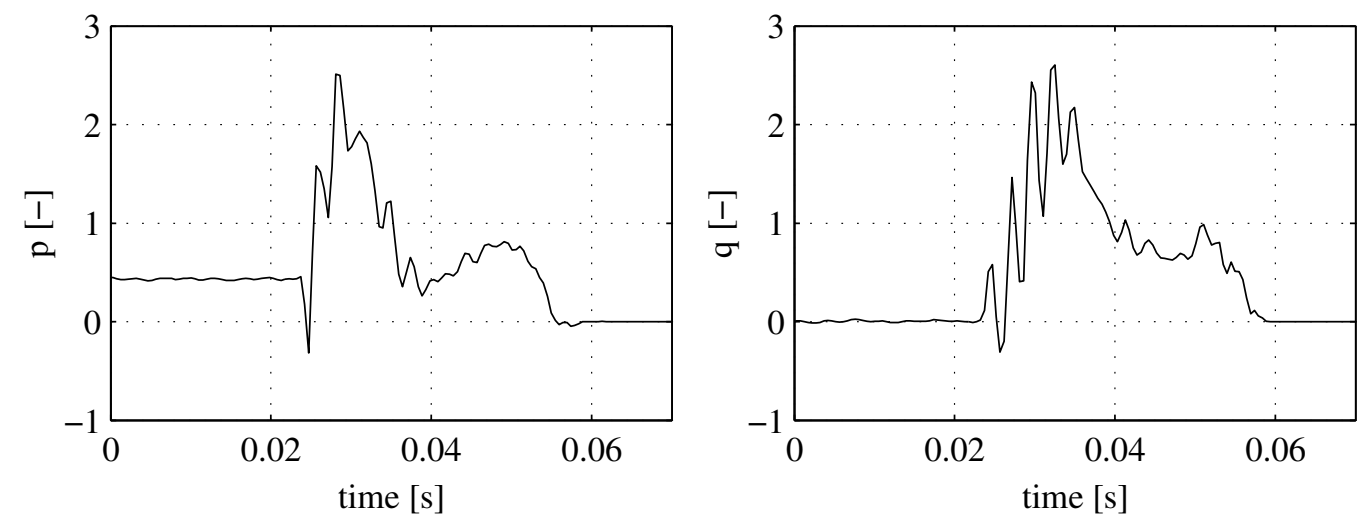

Figure 4.13: Total short-circuit in the near grid at Jung, active (left) and reactive (right) power

to shut down. These results are presented in Publication 9. One occasion with a total short-circuit in the near grid was also recorded. Unfortunately, at the time of this grid fault, the rotor circuit measurement sensors had not yet been installed. Fig. 4.12 and Fig. 4.13 present data recorded during this occasion.

Apart from the data that were the primary interest of the data acquisition process, some other interesting occasions were also recorded. $\mathrm{Y}-\Delta$ generator switching is one of them. The capability to operate at both, a $\mathrm{Y}$ - and a $\Delta$-connection, is established in order to minimize generator losses. Y- $\Delta$ switching is shown in Fig. 4.14 and Fig. 4.15. Some of the higher $P_{s t}$ index values in Fig. 4.8 correspond to the Y- $\Delta$ switching.

Fig. 4.16 and Fig. 4.17 present operation of the wind turbine during a high wind speed period. The utilization of the variable-speed and variable-pitch control is evident and relatively smooth output power can be seen. Fig. 4.18 and Fig. 4.19 show the operation of the wind turbine during a period when the wind speed varies at roughly the rated wind speed of the wind turbine, i.e. about $16 \mathrm{~m} / \mathrm{s}$ [25]. Higher variations in turbine outputs can be seen, as well as a different range of the pitch angle. The variable-speed operation range, however, remains more or less unchanged. 

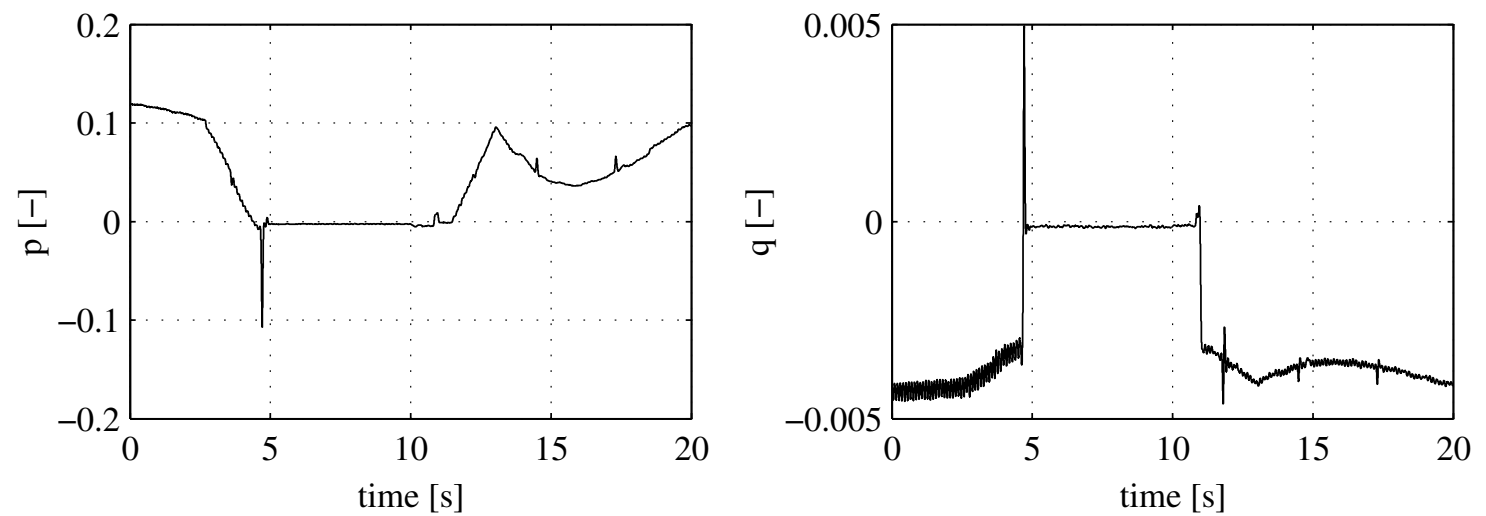

Figure 4.14: Y- $\Delta$ switching at Jung, active (left) and reactive (right) power
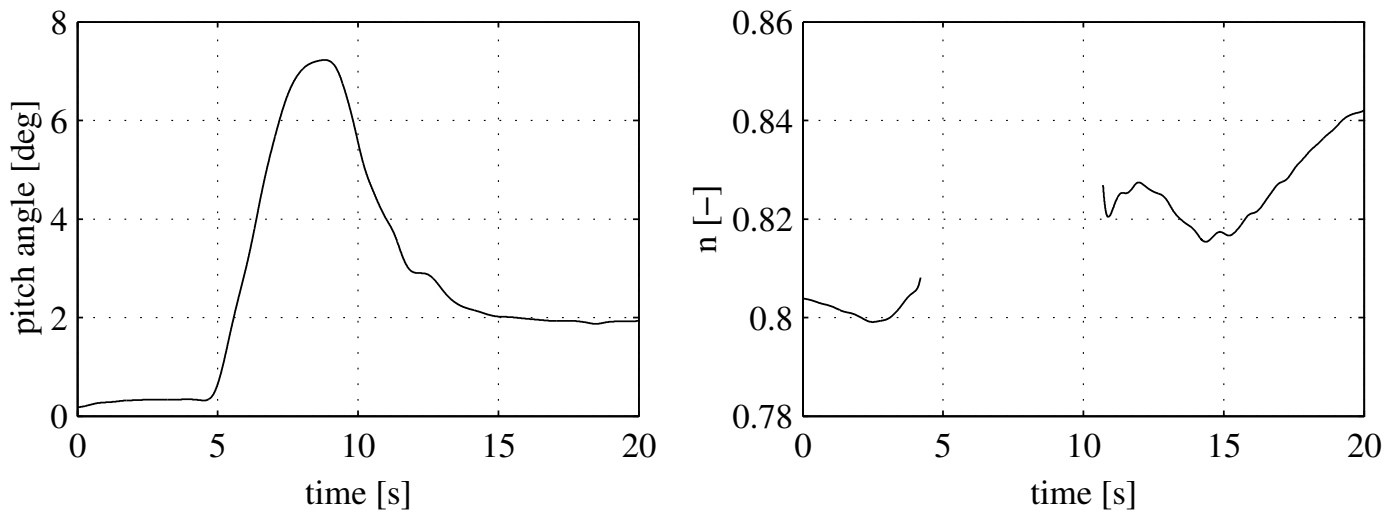

Figure 4.15: Y- $\Delta$ switching at Jung, pitch angle (left) and generator speed (right)
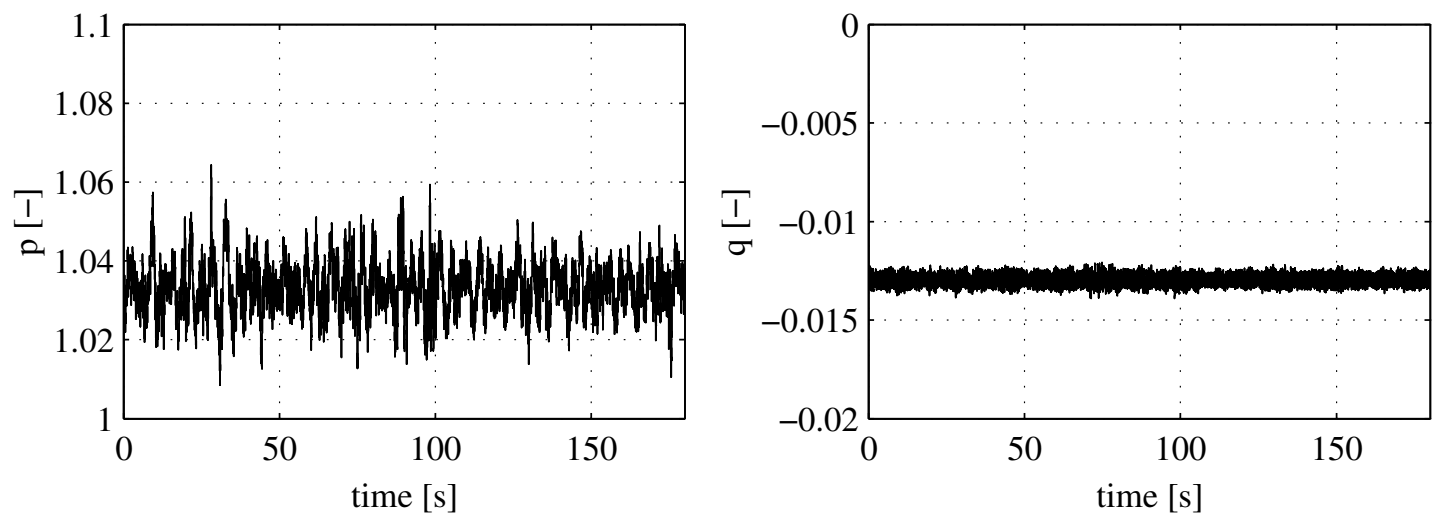

Figure 4.16: High wind speed operation at Jung, active (left) and reactive (right) power 

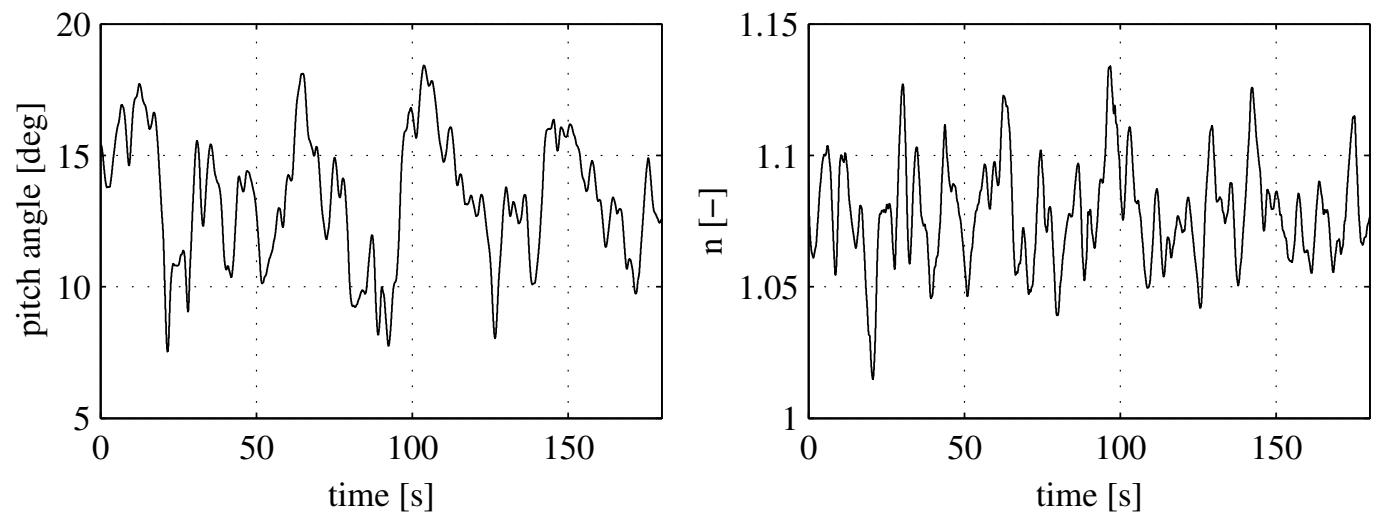

Figure 4.17: High wind speed operation at Jung, pitch angle (left) and generator speed (right)
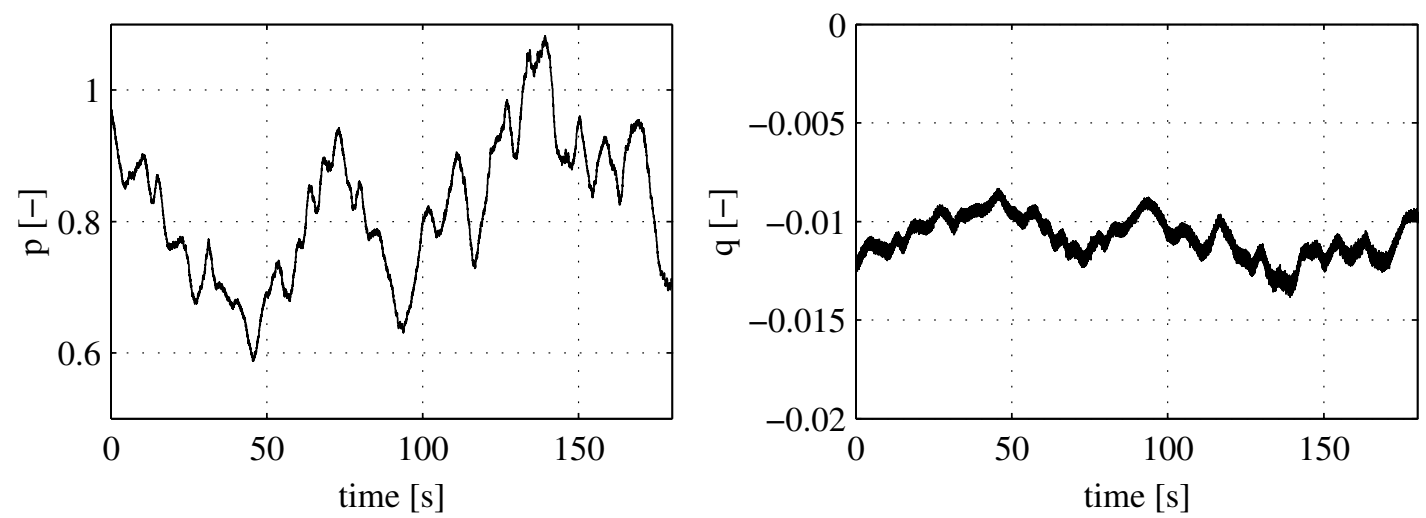

Figure 4.18: Operation at medium wind speed at Jung, active (left) and reactive (right) power
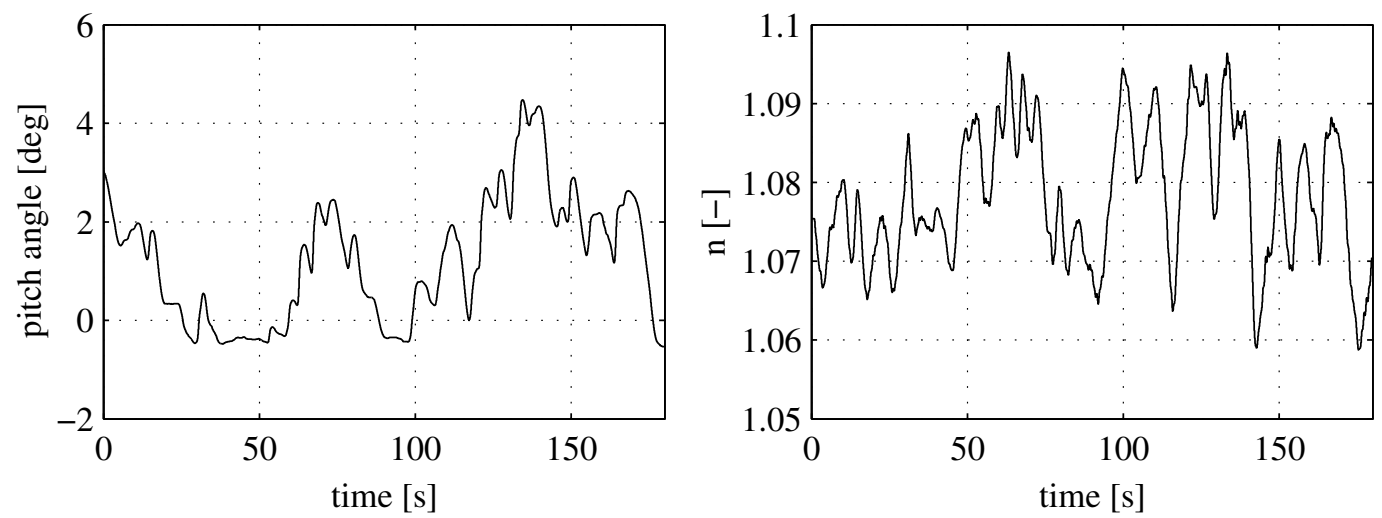

Figure 4.19: Operation at medium wind speed at Jung, pitch angle (left) and generator speed (right) 


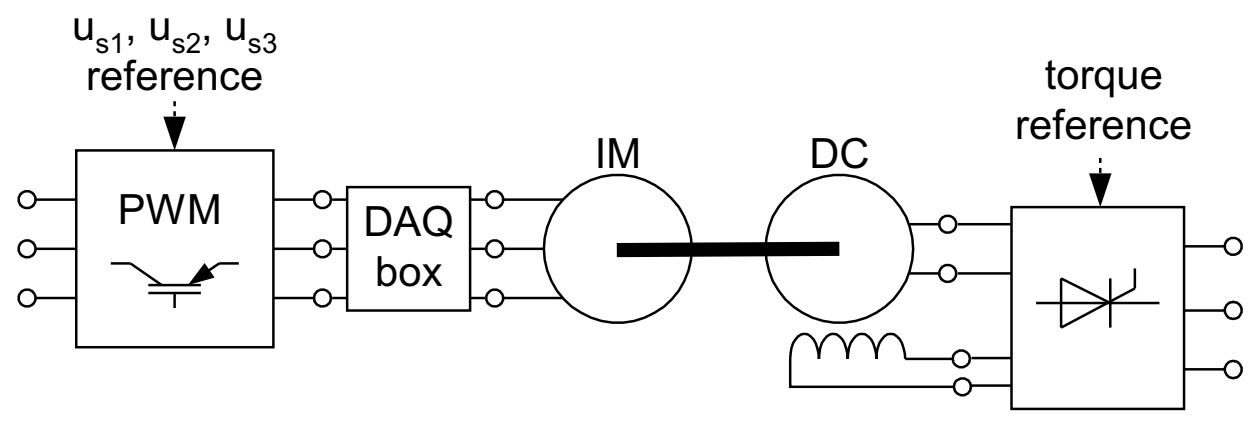

Figure 4.20: Laboratory arrangement

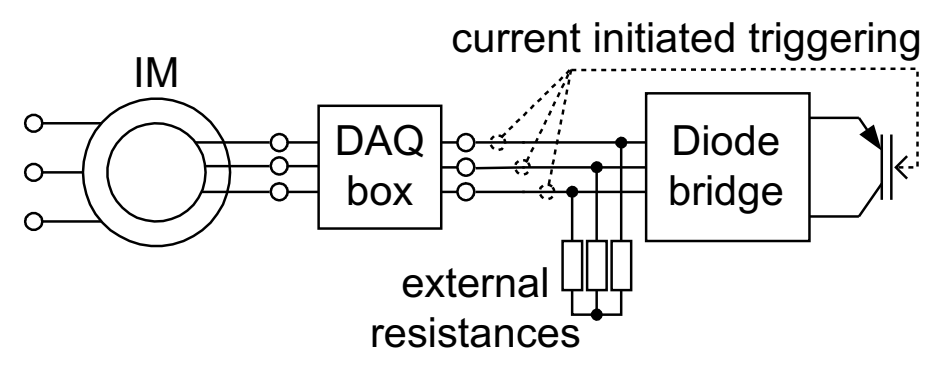

Figure 4.21: Laboratory arrangement of the wound rotor induction machine rotor

\subsection{Laboratory Measurements}

Measurement on a wound rotor and a squirrel cage rotor induction machine were carried out in the laboratory in order to complete field data acquisitions with measurements of the generator responses to grid faults that had not been acquired in field data acquisitions. A programable PWM power electronic converter was used to supply the machine undergoing the measurements and to generate symmetric and asymmetric voltage dips of an arbitrary amplitude. A load on the generator shaft was accomplished using a torque-controlled DC machine supplied with a thyristor converter. The laboratory set up is shown in Fig. 4.20. A data acquisition system with a structure similar to the field data acquisition system, Fig. 4.1, was also used for laboratory measurements.

For measurements on the wound rotor machine, there were external rotor resistances added to the rotor circuit and a rotor current level initiated crow-bar triggered, in case of high currents, was connected in parallel with rotor resistances. The crow-bar was made of a diode bridge with a transistor on the DC side and the current level that initiates crow-bar switching could be freely set. This configuration allows for fast switching and a symmetric connection of all three phases at the same time. Fig. 4.21 presents the basic layout of the circuit discussed.

This circuit configuration can be compared with the one used in the doubly-fed induction machine wind turbine system. Of course, all operational states of the doubly-fed induction machine cannot be achieved using this set up, e.g. subsynchronous generator operation or machine magnetization from the rotor side. However, a pure machine response to grid faults and the impact of crow-bar switch- 
ing can be analyzed and the impact of the control strategy, which is unknown, is eliminated. Detailed control of the doubly-fed induction machine is beyond the scope of this thesis. The interested reader can find more information about the control of a doubly-fed induction machine in [27]. 


\section{Chapter 5}

\section{Wind Turbine Modeling}

The aim of this thesis is to present wind turbine model structures that allow the prediction of the output of a wind turbine during continuous operation as well as during grid disturbances. However, not all commercially available wind turbine systems are considered, here. Based on the discussion presented in Chapter 2 and Chapter 3, the following systems were found to be of interest: A model of fixed-speed stall or active-stall regulated turbine is important for both steady-state impact and grid fault response prediction. Models of variable-speed system turbines are mainly of interest because of their grid fault responses. Since the behavior of these models is significantly influenced by turbine control, it is not possible to reproduce the response of a specific turbine and the models are reduced and generalized accordingly.

\subsection{Steady-State Impact of a Fixed-Speed Wind Turbine}

The stall-regulated fixed-speed system is modeled in Publication 5 and Publication 8. Only a brief summary of that model and the main conclusions are presented here. The considered system consists of four building blocks as presented in Fig. 5.1.

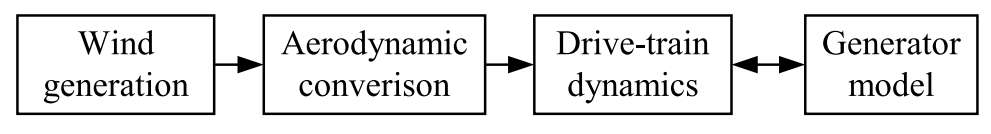

Figure 5.1: Fixed-speed, stall-regulated model structure

Two approaches to simulating wind and aerodynamic conversion are considered and compared. The first approach, the more advanced one, simulates wind distribution over the turbine swept area as suggested in [28]. The simulated wind data are used to calculate force and torque on the turbine blades according to the steady-state aerodynamic theory described in [29] and [30]. The second approach, the simplified one, simulates wind according to [31] at one point only, it applies the aerodynamic filters suggested in [3] and [4] to the generated wind speed data and determines the driving torque from the wind turbine power curve. 
The drive-train system and generator representation are common for both considered models. The drive-train system can be described as a soft shaft connection between the turbine and the generator. The shaft, consequently, is represented by stiffness and absorption. The generator description is based on the Park model [32] of the induction machine. The impact of generator model simplifications by either neglecting stator transient behavior [33] or by neglecting overall generator dynamics are compared.

The model results are compared with field measurements from the Alsvik wind farm that was introduced in Section 4.3. The first comparison is in the frequency domain, and is carried out by comparing the frequency spectra of active and reactive power, Fig. 5.2 and the second comparison is of the $P_{s t}$ turbine impact on a fictive grid, Fig. 5.3.
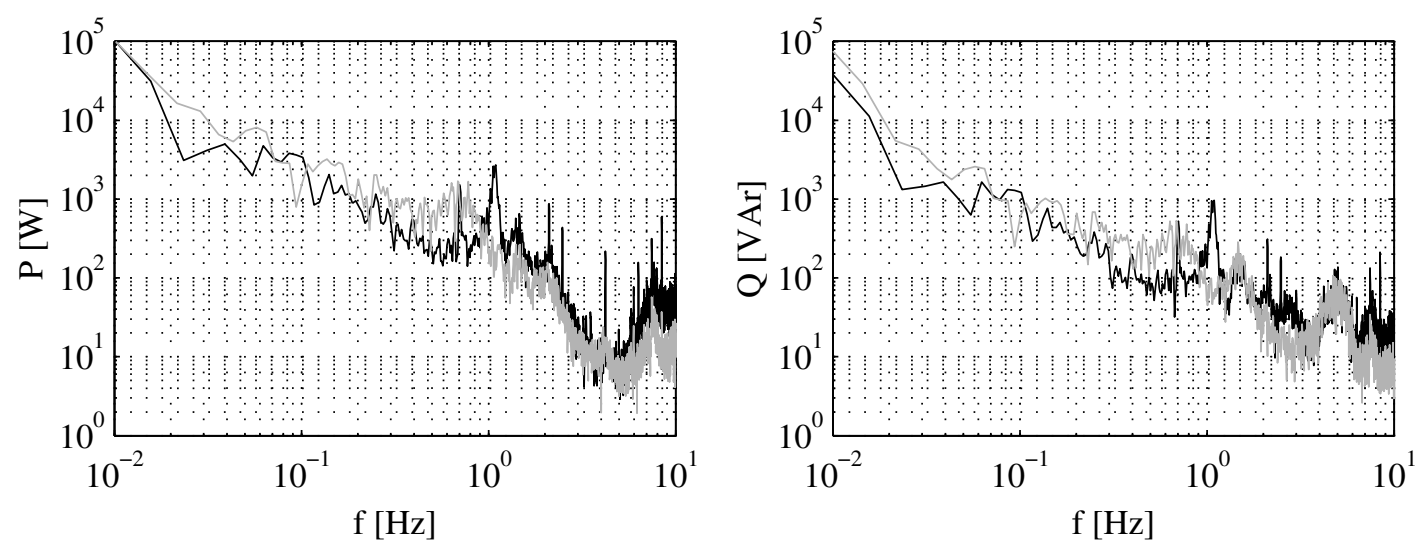

Figure 5.2: Comparison of measured (black) and simulated (gray) active (left) and reactive (right) power
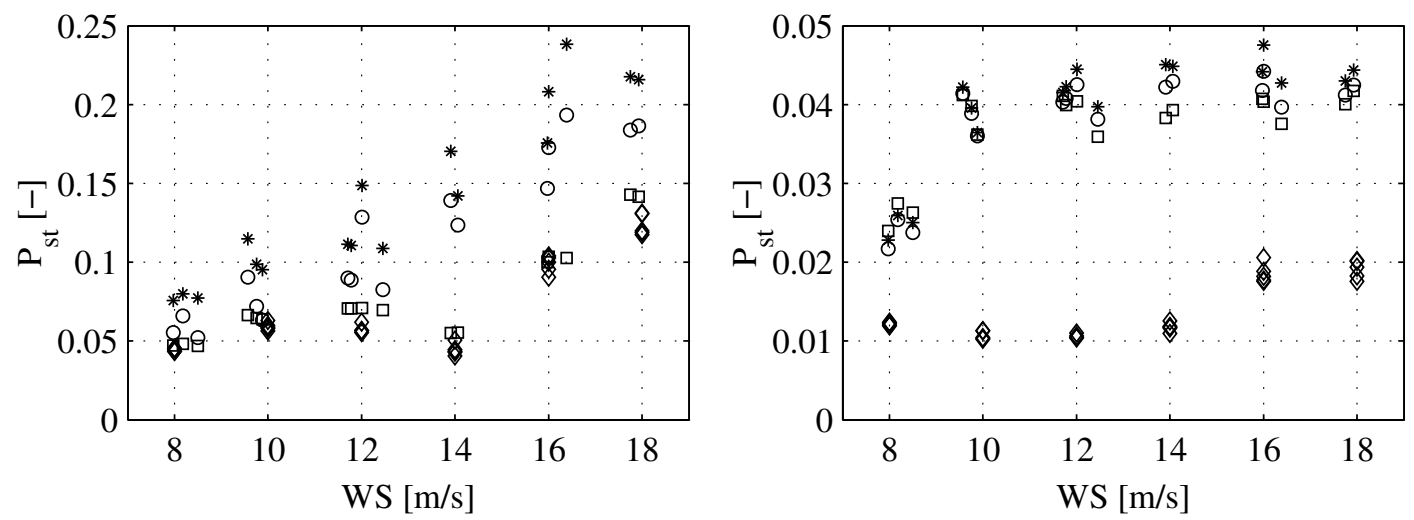

Figure 5.3: Comparison of measured and simulated $P_{s t}$ impact on grid with grid impedance angle of 30deg (left) and 70deg (right), ${ }^{*}$ - measured, o - measured with removed periodic power pulsations, square - simulation with applied measured voltage, rhombus - simulation with applied constant voltage

The main conclusions drawn from the modeling and verification of the presented model are the following: Wind conditions influence the frequency content of the simulated power mainly in the frequency region up to about $0.5 \mathrm{~Hz}$. Blade rotation 
together with drive-train dynamics has the most pronounced impact in the frequency region between $0.5-2.5 \mathrm{~Hz}$. These frequency margins are, however, valid for the $180 \mathrm{~kW}$ turbine considered here. Units with higher rated power would have different margins for these frequency ranges because of their different rotational speed and different drive-train parameters. Most likely, the frequency regions would be lower.

Frequency components above about $4 \mathrm{~Hz}$ are, to a large extent, influenced by grid voltage variations and the conclusion is that the use of measured voltage is essential when evaluating the $P_{s t}$ impact of the turbine. A generator complexity with neglected stator transients [33] appears to be sufficient when evaluating the $P_{s t}$ impact of the turbine. A generator model with stator dynamics included does not provide more accurate results while a generator description with completely neglected dynamics does not provide any result of value.

The use of a simplified approach to wind simulation and aerodynamic conversion is not recommended for predicting $P_{s t}$ impact. The identification of filter parameters is based on the advanced approach and requires a large number of simulations. It is recommended, instead, to calculate the driving torque, in advance, in order to lower the computational burden of the wind turbine model in a grid simulation program. This is possible since the turbine rotational speed can be considered constant and the blade positions are known in advance.

It is assumed that active-stall regulated systems can also be simulated using the presented model structure. The only difference is a slightly different power curve for higher wind speeds. Since the shape of the power curve does not change particularly much, there is no reason to expect a significant impact on the $P_{s t}$ prediction capability of the presented model. The pitch regulation is also unlikely to introduce any major impact on the model performance as it is conducted rather slowly and within a small range.

\subsection{Fault Response of a Fixed-Speed Wind Tur- bine}

The fault response of a fixed-speed wind turbine is, to a great extent, determined by drive-train and generator response. Since driving torque variations are assumed to be slower than the duration of a considered grid fault, the driving torque of the generator shaft is assumed to be constant. Generator models of different complexities were evaluated and compared with measurements, the details are reported in Publication 8.

\subsubsection{Three-Phase Induction Machine Model}

The three-phase induction machine model described in [34] was used as a base for evaluating machine response to symmetric and asymmetric voltage dips. The machine layout considered for the three-phase model is shown in Fig. 5.4 and the 
electric equations that describe one stator phase are presented in Eq. 5.1 to Eq. 5.3. Electric equations for other stator and rotor phases are obtained analogously.

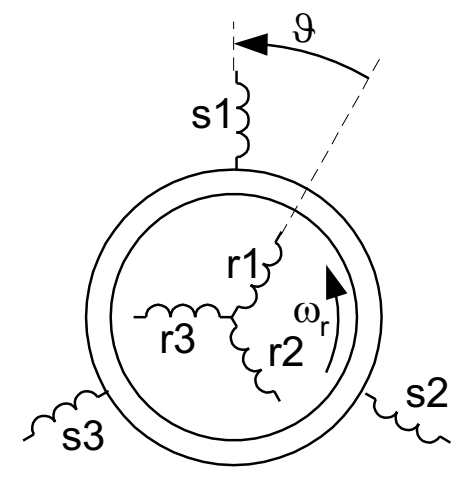

Figure 5.4: Three-phase induction machine layout

$$
\begin{aligned}
u_{s 1} & =R_{s} i_{s 1}+\frac{d \Psi_{s 1}}{d t} \\
\Psi_{s 1} & =\left(L_{s l}+M\right) i_{s 1}+M \cos \left(-\frac{2 \pi}{3}\right) i_{s 2}+M \cos \left(-\frac{4 \pi}{3}\right) i_{s 3}+ \\
& +M \cos (-\vartheta) i_{r 1}+M \cos \left(-\vartheta-\frac{2 \pi}{3}\right) i_{r 2}+M \cos \left(-\vartheta-\frac{4 \pi}{3}\right) i_{r 3} \\
T_{s 1} & =n_{p} M i_{s 1}\left[i_{r 1} \sin (-\vartheta)+i_{r 2} \sin \left(-\vartheta-\frac{2 \pi}{3}\right)+i_{r 3} \sin \left(-\vartheta+\frac{2 \pi}{3}\right)\right]
\end{aligned}
$$

The model form has, however, been changed. Since the neutral point is not connected, one stator and one rotor current were eliminated and expressed with the use of the other two currents in the stator and rotor, respectively, Eq. 5.4 and Eq. 5.5. This has led to the elimination of two state variables.

$$
\begin{aligned}
& i_{s 3}=-i_{s 1}-i_{s 2} \\
& i_{r 3}=-i_{r 1}-i_{r 2}
\end{aligned}
$$

In order to avoid the use of phase voltages that refer to the machine neutral point, the machine voltage equations were rewritten for main voltages. Eq. 5.6 shows the principle. The order of the system was not changed but the machine description is now independent of the voltage zero sequence component.

$$
u_{s 1, s 2}=R_{s} i_{s 1}+\frac{d \Psi_{s 1}}{d t}-R_{s} i_{s 2}-\frac{d \Psi_{s 2}}{d t}
$$

The presented model consists of four electric differential equations that are to be completed with the standard mechanic differential equation, Eq. 5.7.

$$
J \frac{d \omega_{r}}{d t}=T_{e l m g}-T_{l}
$$




\subsubsection{Two-axis Model of an Induction Machine}

The presented three-phase model is seldom used and a two-axis model using the space vector representation [32] is often employed, instead, Eq. 5.8 to Eq. 5.12. However, a small modification of the space vector determination is necessary in order to obtain a correct response of the model supplied with an asymmetric voltage. The voltage space vector is to be determined from the main grid voltages and, for convenience, is scaled down and phase-shifted to correspond with the phase voltage description, Eq. 5.13. The use of the main voltages in the voltage space vector transformation inherently ensures that the sum of the used voltages is zero, as required by the space vector definition, Eq. 5.13 and Eq. 5.14.

$$
\begin{aligned}
\widehat{u}_{s} & =R_{s} \widehat{i}_{s}+j \omega_{1}\left(L_{s l}+L_{m}\right) \widehat{i}_{s}+j \omega_{1} L_{m} \widehat{i}_{r}+\left(L_{s l}+L_{m}\right) \frac{d \widehat{i}_{s}}{d t}+L_{m} \frac{\widehat{d i_{r}}}{d t} \\
\widehat{u}_{r} & =j \omega_{2} L_{m} \widehat{i}_{s}+R_{r} \widehat{i}_{r}+j \omega_{2}\left(L_{r l}+L_{m}\right) \widehat{i}_{r}+L_{m} \frac{\widehat{d i}_{s}}{d t}+\left(L_{r l}+L_{m}\right) \frac{\widehat{d i_{r}}}{d t} \\
\widehat{\Psi}_{s} & =\left(L_{s l}+L_{m}\right) \widehat{i}_{s}+L_{m} \widehat{i}_{r} \\
\widehat{\Psi}_{r} & =L_{m} \widehat{i}_{s}+\left(L_{r l}+L_{m}\right) \widehat{i}_{r} \\
T_{e l m g} & =-\frac{3 n_{p}}{2 k_{a b}^{2}} \operatorname{Im}\left[\widehat{i}_{s} \widehat{\Psi}_{s}^{*}\right] \\
\widehat{u}_{s} & =k_{a b}\left[u_{s 1, s 2}+\frac{j}{\sqrt{3}}\left(u_{s 2, s 3}-u_{s 3, s 1}\right)\right] \frac{e^{-j \frac{\pi}{6}}}{\sqrt{3}} \\
0 & =u_{s 1, s 2}+u_{s 2, s 3}+u_{s 3, s 1}
\end{aligned}
$$

The results obtained using the three-phase and the two-axis models have been compared. Supply voltage asymmetry has been achieved by changing negative and zero sequence voltage components. The outcome of the two presented models did not differ at all. The two-axis model, however, requires less computational capacity even if the order of both models is equal and is used for the induction machine representation in the following.

\subsubsection{Higher Order Model of the Induction Machine}

Induction machine parameters are often considered constant. However, high currents in the machine during grid faults cause saturation of the leakage inductances. Rotor circuit resistance may also vary due to the skin effect of the rotor bars that affects the rotor currents that follow the machine transient behavior. A higher order model of the induction machine that incorporates a description of these aspects is presented in [12]. An equivalent circuit that takes these two aspects into account is presented in Fig. 5.5.

Details of this model can be found in [35]. It should be pointed out, however, that the parameter determination of such a model requires a number of non-standard measurements on the induction machine, which are not readily available. Moreover, 
such a complex model is mainly of importance when predicting very short-term, initial surge currents. For example, such a complex model is useful for dimensioning switch-gear and connecting equipment. In case of power system interaction studies, such a detailed model is unnecessary. It should be also pointed out that the higher order model representation requires a shorter simulation step and this feature is highly undesirable in power system simulation studies.

\subsubsection{Experimental Verification}

Simulations and measurements of the induction machine response to symmetric and asymmetric voltage dips have been simulated and measured for a $15 \mathrm{~kW}$ squirrel cage rotor machine. The machine was operated either as a motor or as a generator and the load level varied from no-load to full load. The amplitude of the applied voltage dips has also been changed from $80 \%$ down to $0 \%$, i.e. a short-circuit of the stator windings. The results presented in the following plots correspond to $100 \%$ loaded generator operation and the applied $60 \%$ voltage dip. Fig. 5.6 to Fig. 5.8 present the machine response to a symmetric dip and Fig. 5.9 to Fig. 5.11 present the response of the machine to an asymmetric dip.

Only results simulated using the standard two-axis induction machine model are presented. The use of the higher order induction machine model, Section 5.2.3, did not produce more accurate results. The difference between the outcomes of the two models was only marginal. It is concluded, therefore, that the two-axis model representation is good enough to provide reasonably accurate results.

The agreement between measurements and simulations is very good during the first line period after the voltage dip occurs. However, the accuracy during the following line periods is not as good. Possible reasons for this disagreement are the stability of the load torque on the machine shaft (the DC machine) or the accuracy of the moment of inertia of the induction and DC machines.

Measurements and simulations of other cases with different load levels and different voltage dips produced fairly similar results. Publication 8 presents a comparison of measurements on a $180 \mathrm{~kW}$ fixed-speed stall-regulated turbine with simulations. Publication 8 also concludes that the two-axis model of the induction machine is capable of predicting a reasonably accurate response of the induction machine to supply voltage dips.

\subsection{Fault Response of Variable-Speed Wind Tur- bines}

The fault response of variable-speed systems is, to a large extent, influenced by the power electronic converter. A modern power electronic converter can theoretically maintain the desired output current almost regardless of the grid voltage, provided that the current and voltage limits of the converter are not violated, and that driving energy from the wind turbine is available. 


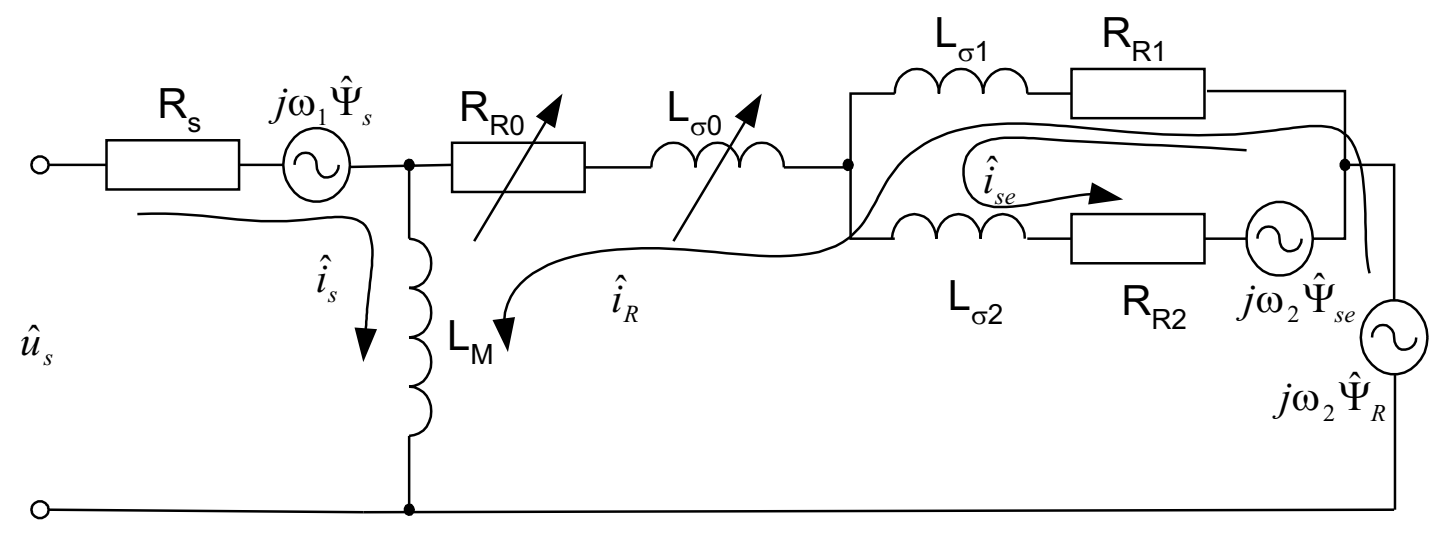

Figure 5.5: Higher order induction machine model, equivalent circuit
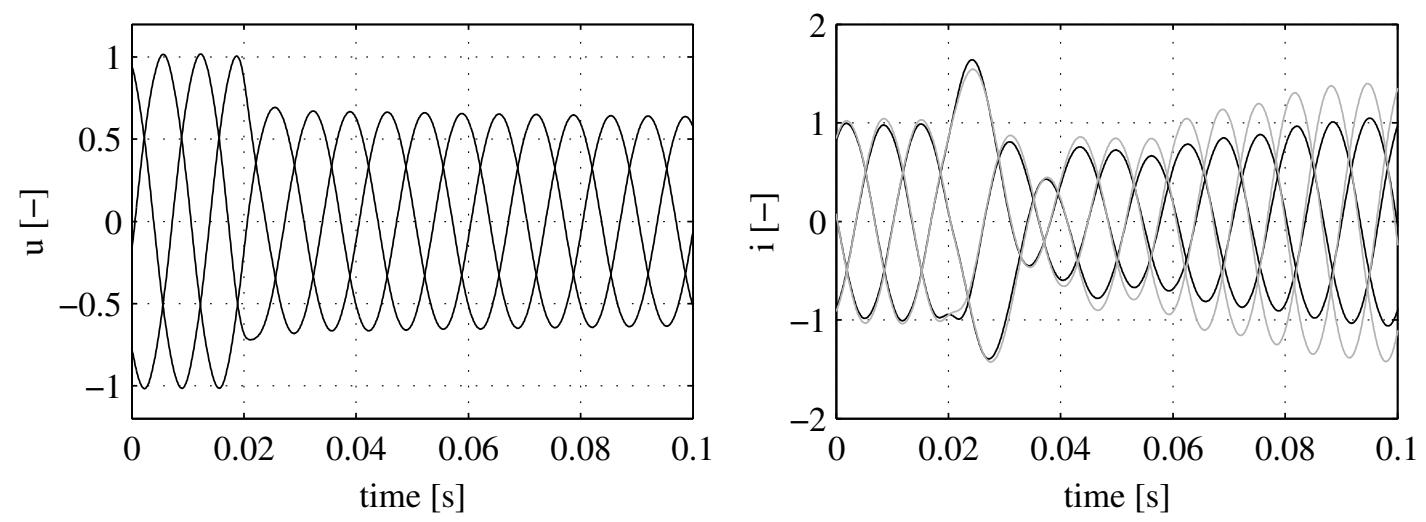

Figure 5.6: Applied measured main voltages (left) and measured (black) and simulated (gray) phase currents (right) of a laboratory $15 \mathrm{~kW}$ induction machine with applied symmetric voltage dip
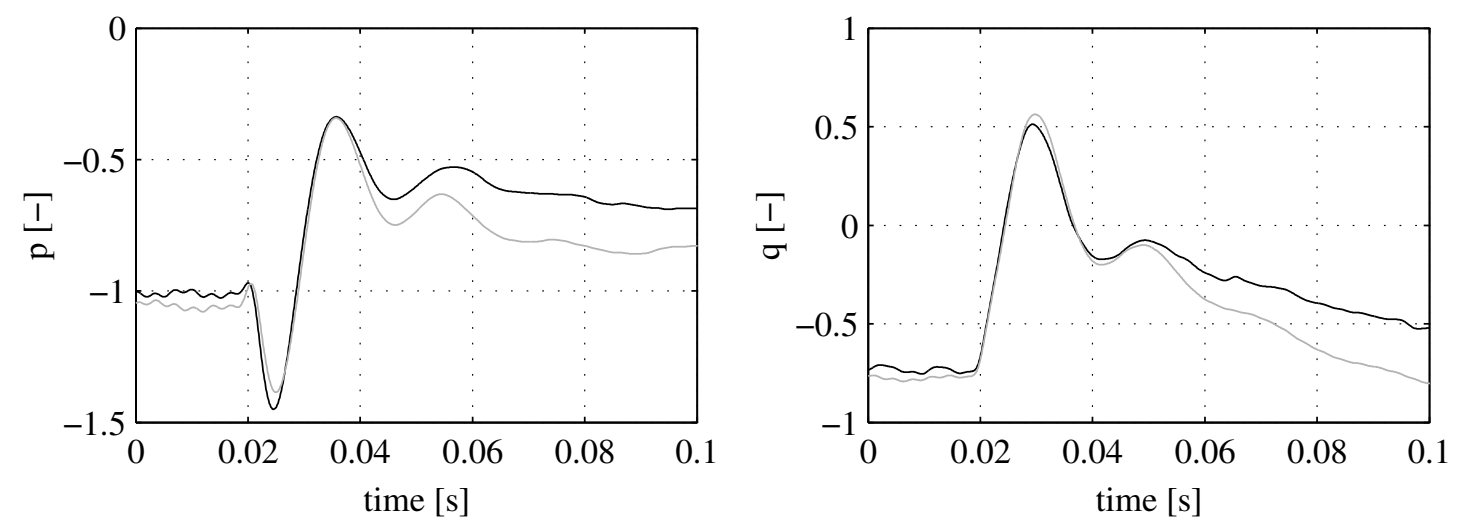

Figure 5.7: Measured (black) and simulated (gray) active (left) and reactive (right) power of a laboratory $15 \mathrm{~kW}$ induction machine with applied symmetric voltage dip 


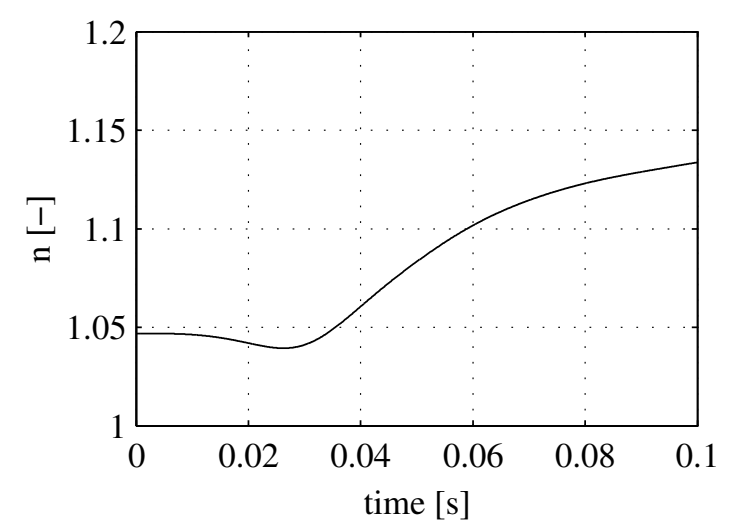

Figure 5.8: Simulated machine speed of a laboratory $15 \mathrm{~kW}$ induction machine with applied symmetric voltage dip
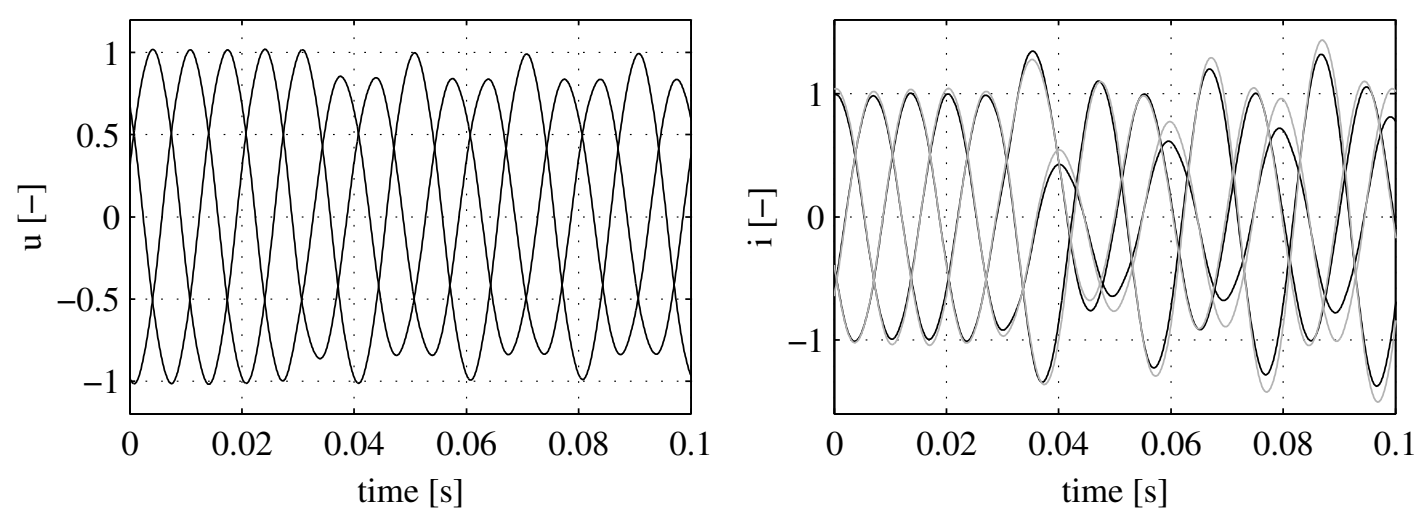

Figure 5.9: Applied measured main voltages (left) and measured (black) and simulated (gray) phase currents (right) of a laboratory $15 \mathrm{~kW}$ induction machine with applied asymmetric voltage dip
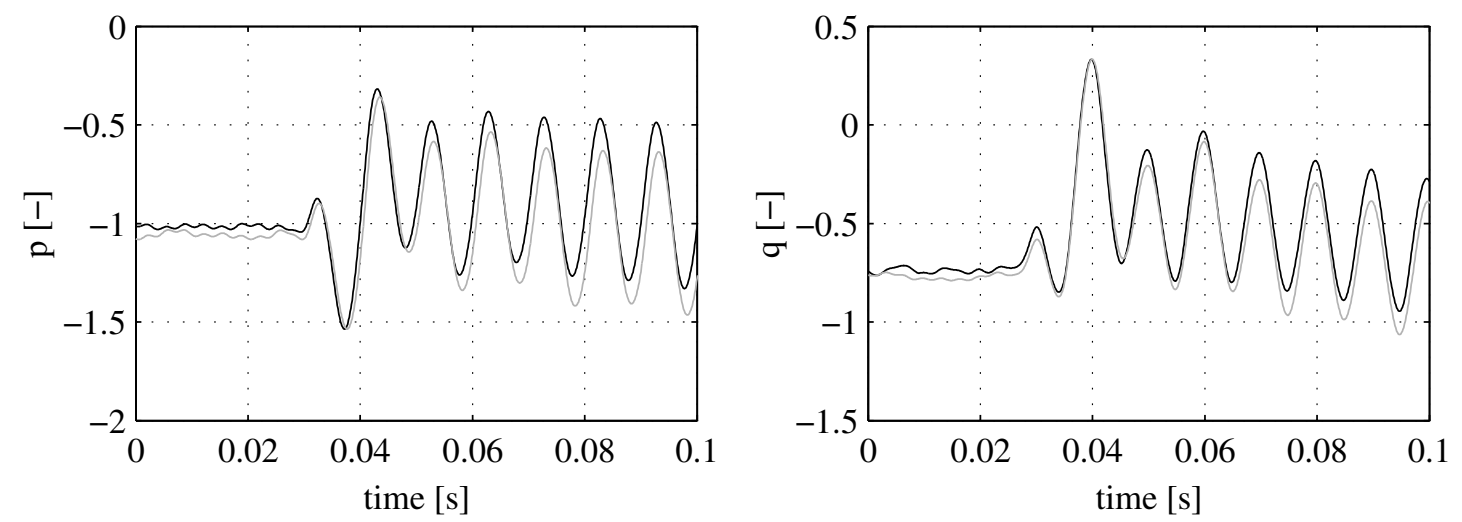

Figure 5.10: Measured (black) and simulated (gray) active (left) and reactive (right) power of a laboratory $15 \mathrm{~kW}$ induction machine with applied asymmetric voltage dip 


\subsubsection{Variable-Speed System Connected via Power Elec- tronic Converter in the Stator Circuit}

It is reasonable to assume that the response of the wind turbine system connected to the grid via a power electronic converter in the stator circuit is, to a high degree, determined by the power electronic converter. A specific response of this wind turbine system could be ordered in advance by the utility companies and the corresponding model representation must contain this information that describes the control algorithms of the wind turbine and its electrical system.

\subsubsection{Variable-Speed System with Doubly-Fed Induction Generator}

The response of the variable-speed system with a doubly-fed induction generator is composed of the responses of the controlled induction machine and of the power electronic converter. The principal layout of the considered system is presented in Fig. 5.12.

The response of the power electronic converter is, again, to a great extent, determined by the power electronic converter control and dimensioning. The response of the induction machine is, however, influenced by the machine parameters as well as the machine control and must be treated separately.

The magnetic flux in the induction machine cannot change instantaneously and this means that a sudden change in the stator supply voltage will be followed by a large change in the machine currents. The rotor-connected converter must respond to the change in the rotor currents so that the rotor currents are maintained as required by the machine control. Since the rotor converter output voltages and currents are limited, the rotor converter may not be able to maintain the rotor currents within given limits during more severe grid faults and must be disconnected. In such a case, the rotor circuit needs to be short-circuited in order to prevent overvoltages and the machine can then be modeled as a standard induction machine with a squirrel cage rotor. The disconnection of the stator circuit that follows the rotor converter disconnection has a minimum time delay of one or two grid periods.

The preceding considerations suggest to treat fault response prediction of the doublyfed induction machine in two ways. For less severe grid faults, which the wind turbine can withstand without any need for disconnection, the system should be modeled with the converter control algorithms included in the model. For a case with more severe grid faults, which are followed by rotor converter disconnection, there is no need to involve a model of the rotor converter, and the rotor currents and speed at the fault instant are used as the initial values of the squirrel cage induction machine model.

In either case, a grid-connected converter could be utilized to reduce generator impact to the grid. However, it is likely that this alternative is only of interest for less severe grid disturbances since the converter rating would not be enough to compensate for the higher currents expected during major grid faults. 


\subsubsection{Control of Doubly-Fed Induction Generator}

In order to analyze the behavior of a doubly-fed induction generator, a basic overview of the control principle is given here.

It is convenient to describe an induction machine with the $\Gamma$-model representation when control of a doubly-fed machine is of interest. The $\Gamma$-model equivalent circuit is given in Fig. 5.13, Eq. 5.15 to Eq. 5.18 present the determination of the circuit parameters and Eq. 5.19 to Eq. 5.21 describe the transient behavior of the machine. More on transformation between different model representations can be found in $[36]$.

$$
\begin{gathered}
\gamma=\frac{L_{m}+L_{s l}}{L_{m}} \\
L_{M}=\gamma L_{m} \\
R_{R}=\gamma^{2} R_{r} \\
L_{\sigma}=\gamma L_{s l}+\gamma^{2} L_{m} \\
\frac{d \widehat{\psi}_{s}}{d t}=\widehat{u}_{s}-\left(\frac{R_{s}}{L_{M}}+j \omega_{1}\right) \widehat{\psi}_{s}+R_{s} \widehat{i}_{R} \\
L_{\sigma} \frac{d \hat{i}_{R}}{d t}=\widehat{u}_{R}-\widehat{u}_{s}-\left(R_{s}+R_{R}+j \omega_{2} L_{\sigma}\right) \widehat{i}_{R}+\left(\frac{R_{s}}{L_{M}}+j \omega_{r}\right) \widehat{\psi}_{s} \\
J \frac{d \omega_{r}}{d t}=\frac{3 n_{p}^{2}}{2 k_{a b}^{2}} \operatorname{Im}\left\{-\widehat{\psi}_{s}^{*} \widehat{i}_{R}\right\}-n_{p} T_{l}
\end{gathered}
$$

The design of the rotor current controller is based on the machine rotor equation, Eq. 5.20. The voltage $\widehat{u}_{R}$ can be substituted according to Eq. 5.22.

$$
\widehat{u}_{R}=\widehat{u}_{R}^{\prime}-\left(R_{a}-j \omega_{2} L_{\sigma}\right) \widehat{i}_{R}-\left(j \omega_{r}+\frac{R_{s}}{L_{M}}\right) \widehat{\psi}_{s}+\widehat{u}_{s}
$$

The substitution presented in Eq. 5.22 introduces an active damping resistance, $R_{a}$, a term that removes the cross-coupling between real and imaginary parts of the rotor current and the voltage, $j \omega_{2} L_{\sigma}$, and a feed-forward coupling of the back electromotive force (back EMF), $\left(j \omega_{r}+\frac{R_{s}}{L_{M}}\right) \widehat{\psi}_{s}+\widehat{u}_{s}$. More detailed treatment and analysis of these terms can be found in [27]. The use of the introduced substitution simplifies the rotor equation, Eq. 5.20, to the form presented in Eq. 5.23, which can be described with a corresponding transfer function, Eq. 5.24.

$$
\begin{aligned}
L_{\sigma} \frac{\widehat{d i}_{R}}{d t} & =\widehat{u}_{R}^{\prime}-\left(R_{s}+R_{R}+R_{a}\right) \widehat{i}_{R} \\
F(s) & =\frac{1}{s L_{\sigma}+R_{s}+R_{R}+R_{a}}
\end{aligned}
$$




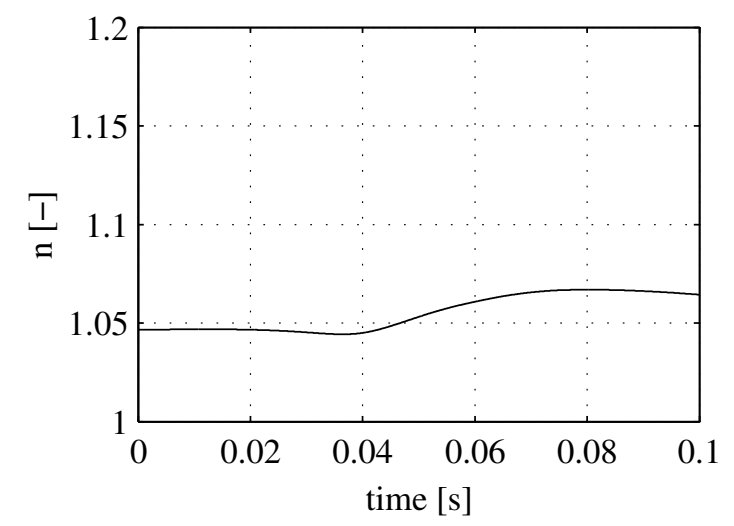

Figure 5.11: Simulated machine speed of a laboratory $15 \mathrm{~kW}$ induction machine with applied asymmetric voltage dip

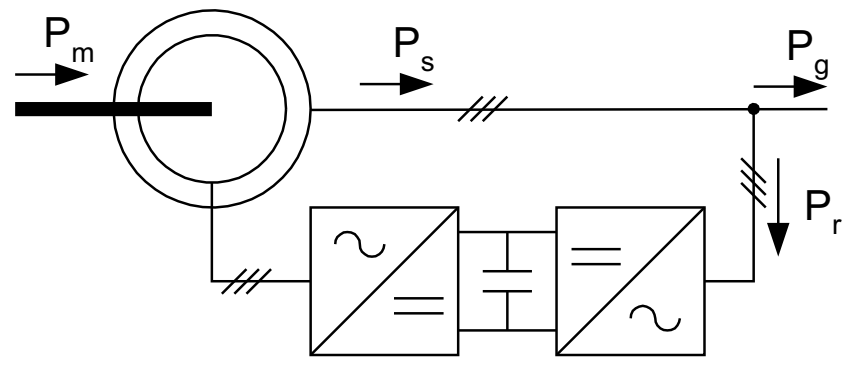

Figure 5.12: Doubly-fed induction machine principal layout

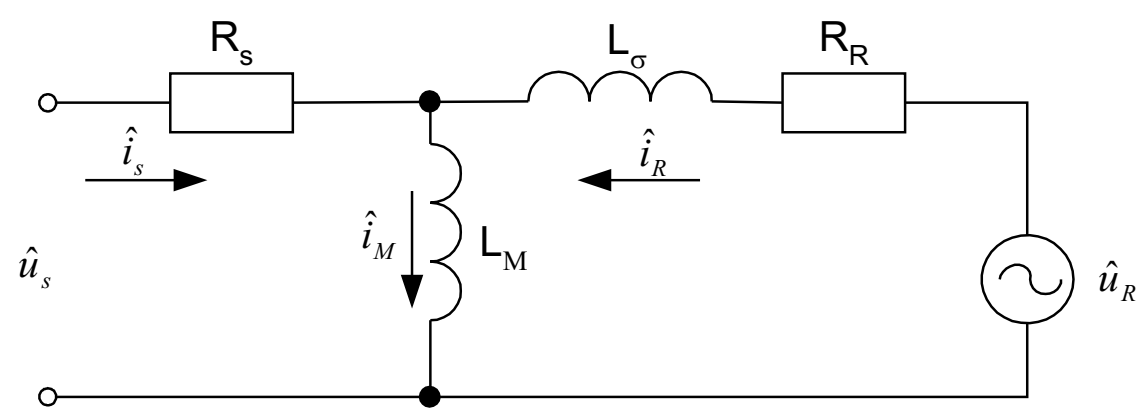

Figure 5.13: $\Gamma$-model of induction machine 
The rotor current PI-controller can now be designed. The method of internal model control described in [37] can be used, for example, and the PI-controller constants $k_{p}$ and $k_{i}$, as well as the active damping resistance, $R_{a}$, are those determined according to Eq. 5.25 to Eq.5.27, where $\alpha_{e}$ stays for the current control closed-loop system bandwidth.

$$
\begin{aligned}
R_{a} & =\alpha_{e} L_{\sigma}-\left(R_{s}+R_{R}\right) \\
k_{p} & =\alpha_{e} L_{\sigma} \\
k_{i} & =\alpha_{e}\left(R_{s}+R_{R}+R_{a}\right)
\end{aligned}
$$

The block diagram in Fig. 5.14 gives an overview of the rotor current control considered in this thesis and Eq. 5.28 describes the resulting rotor voltage $\widehat{u}_{R}$.

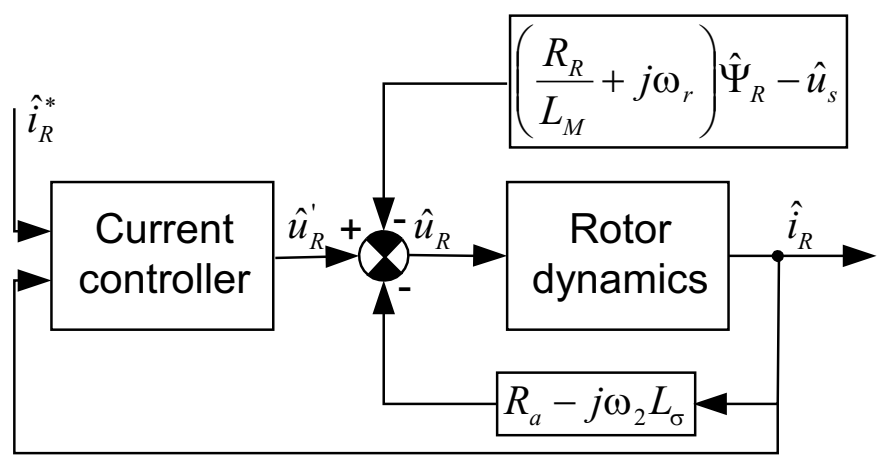

Figure 5.14: Block diagram of the rotor current control

$$
\begin{aligned}
\widehat{u}_{R} & \left.=k_{p} \widehat{i}_{R}^{*}-\widehat{i}_{R}\right)+\int_{0}^{t}\left(\widehat{i}_{R}^{*}-\widehat{i}_{R}\right) d t \\
& -\left(R_{a}-j \omega_{2} L_{\sigma}\right) \widehat{i}_{R}-\left(\frac{R_{s}}{L_{M}}+j \omega_{r}\right) \widehat{\psi}_{s}+\widehat{u}_{s}
\end{aligned}
$$

Control of the doubly-fed induction machine can be treated even further. That, however, is beyond the scope of this thesis. The interested reader can find more information and analysis in [27]. Topics, such as stator flux estimation, sensorless operation and torque and speed control are treated there.

\subsubsection{Fault Response of Controlled Doubly-Fed Induction Generator}

The response of the doubly-fed induction generator to a symmetric voltage dip has been simulated and measured. The simulated system uses the parameters of the laboratory $3 \mathrm{~kW}$ machine and the control strategy described in Section 5.3.3 while the recorded data have been collected from the Vestas $850 \mathrm{~kW}$ wind turbine introduced 
in Section 4.4. Observe that the response recorded for the Vestas turbine includes the response of the grid side converter while the presented simulated response only comprises the machine response. In both cases, the machine operates as a generator with about $20 \%$ load and a symmetric $80 \%$ voltage dip is applied to the machine. Fig. 5.15 and Fig. 5.16 present the applied voltage and the response of the simulated system while Fig. 5.17 and Fig. 5.18 present the measured voltage and the response of the Vestas $850 \mathrm{~kW}$ wind turbine at Jung.

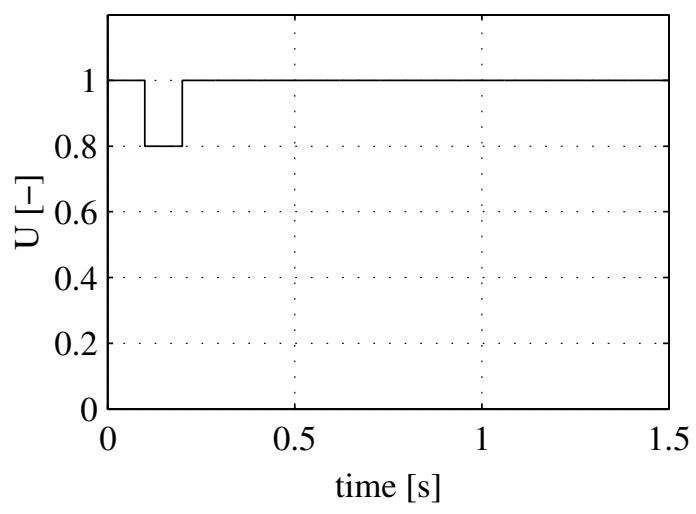

Figure 5.15: Small voltage dip applied to the simulated 3kW machine
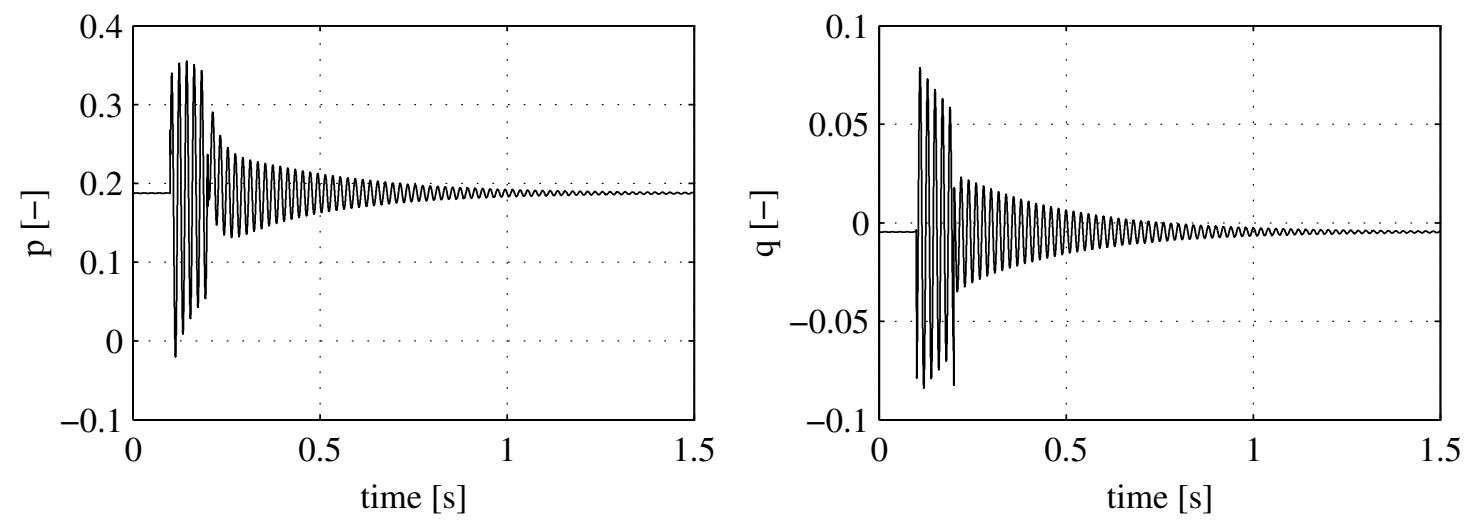

Figure 5.16: Response of the simulated $3 \mathrm{~kW}$ machine to the small voltage dip in Fig. 5.15, active (left) and reactive (right) power

It can be seen that there are similarities in the response of the two compared systems. Both systems respond to the voltage dip with purely damped oscillations in active and reactive power with a frequency of $50 \mathrm{~Hz}$ caused by poorly damped eigenvalues of the system, [27]. The difference in the amplitude and duration of the measured and simulated oscillations is likely due to different machine data, differences in control details and it is likely that the response of the Vestas system is influenced by the grid-connected power electronic converter that is not considered in the presented simulations. More details about the behavior of a doubly-fed system can be found in Publication 9 and [27].

The impact of the doubly-fed system on the grid during smaller voltage dips can be, from the power system point of view, considered as negligible since the amplitude and duration of the presented oscillations are unlikely to cause any power system 


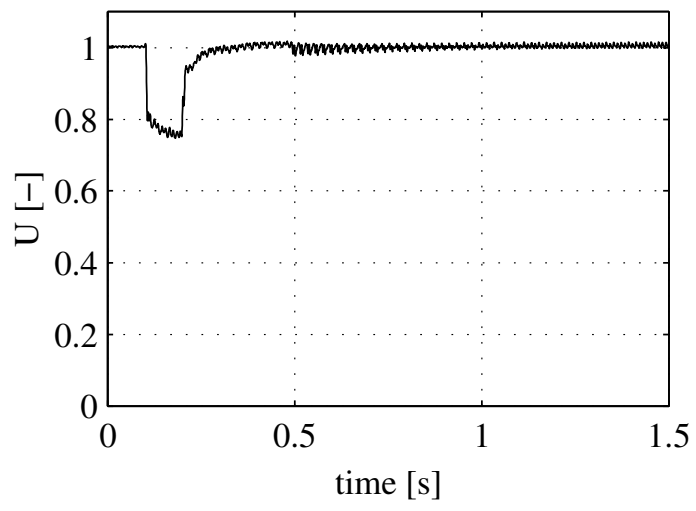

Figure 5.17: Measured voltage dip of the Vestas $850 \mathrm{~kW}$ wind turbine
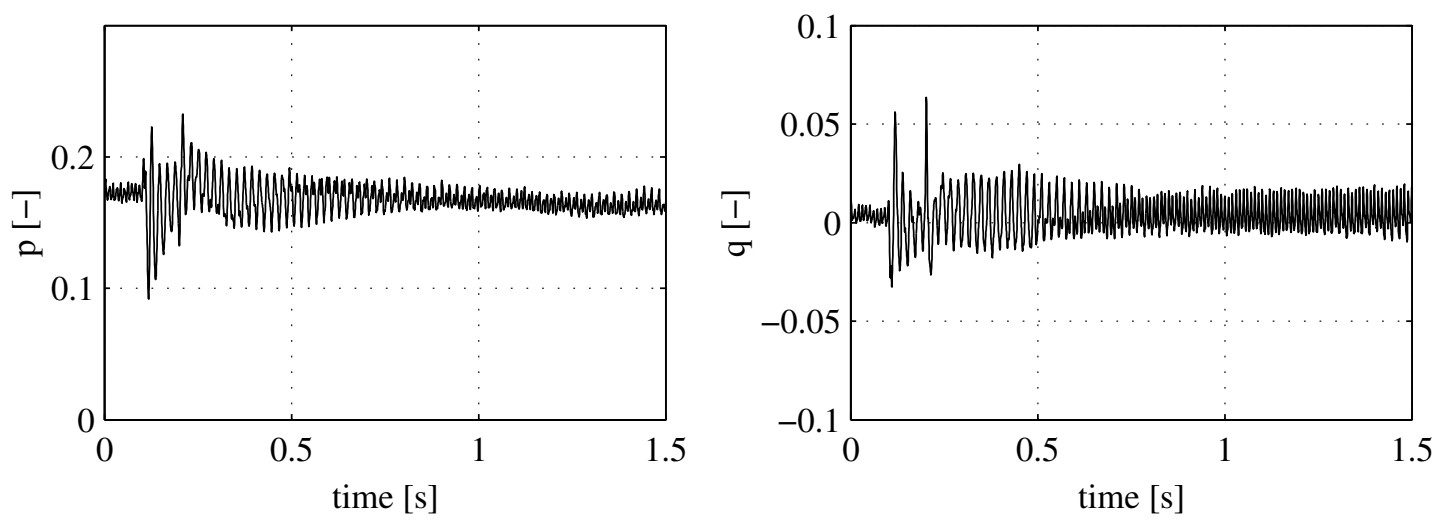

Figure 5.18: Measured response of the Vestas $850 \mathrm{~kW}$ wind turbine, active (left) and reactive (right) power 
instability. This means that as long as the grid voltage dip is small enough not to cause any rotor circuit crow-bar action, i.e. that the response of the system can be handled by the rotor converter, the turbine can be considered as a source of constant active and reactive power. However, a response of the doubly-fed system to more serious fault cases, e.g. more severe voltage dips, that cannot be handled by the rotor converter causes a more pronounced impact on the grid as discussed earlier in Section 5.3.2. This type of event is treated more in the following section.

\subsubsection{Impact of Crow-bar Switching}

The impact of crow-bar switching has been measured and analyzed on the laboratory measurement setup described in Section 4.5. The machine was driven to a desired operating point and the response to an imposed stator voltage disturbance was registered.

A standard induction machine model described in Section 5.2 .2 can be used for the simulation of the machine response in this case. However, the model must be initiated at the given operating point, which is the way to represent the response of the system that follows a crow-bar switching action.

Results of measurements and simulations for two different occasions, on which crowbar switching occurred are presented here. Fig. 5.19 and Fig. 5.20 show the measured and simulated machine response to a symmetric $40 \%$ voltage dip for a $20 \%$ loaded generator. The measured main voltages that were also used as the inputs for the simulated model are presented in Fig. 5.19 and the active and reactive power responses are presented in Fig. 5.20. Analogous plots that hold for an asymmetric $60 \%$ voltage dip applied to a 50\% loaded generator are presented in Fig. 5.21 and Fig. 5.22.

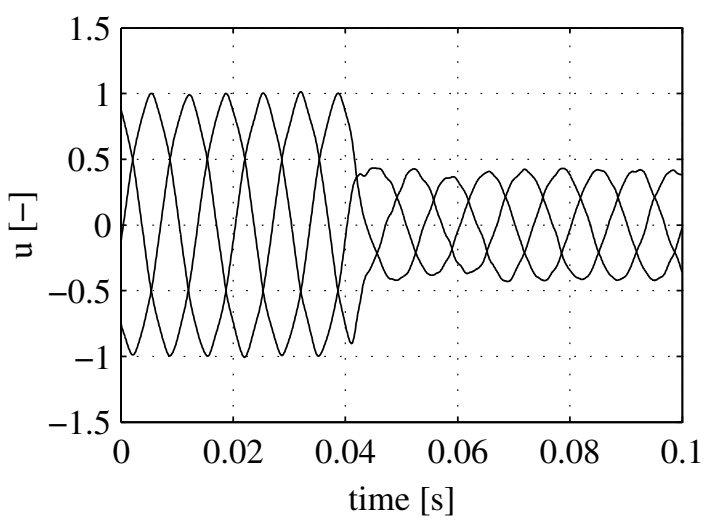

Figure 5.19: The measured main voltages of the laboratory $3 \mathrm{~kW}$ machine that correspond to a symmetric $40 \%$ voltage dip

It can be seen that the simulated and measured results show good agreement.

In the case of a system with a rotor power electronic converter, there is the potential to magnetize the machine via the rotor. Both the stator and the rotor machine magnetization, have advantages and disadvantages. As concluded in [27], the machine 

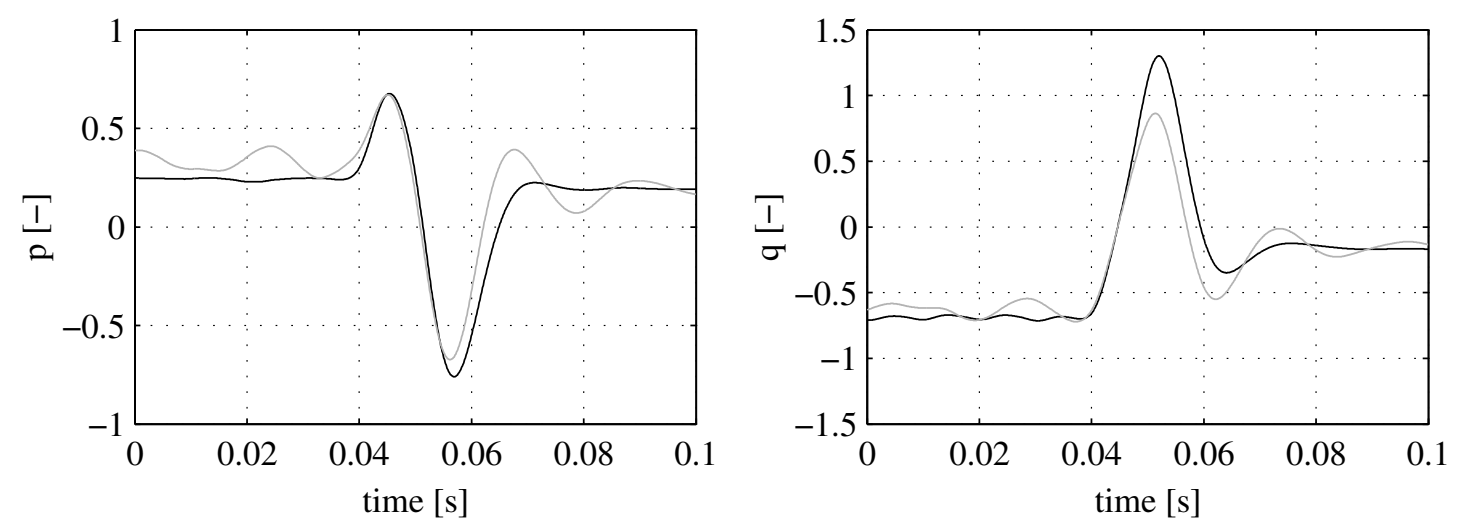

Figure 5.20: The measured (black) and simulated (gray) response of the laboratory $3 \mathrm{~kW}$ machine to a symmetric $40 \%$ voltage dip, active (left) and reactive (right) power

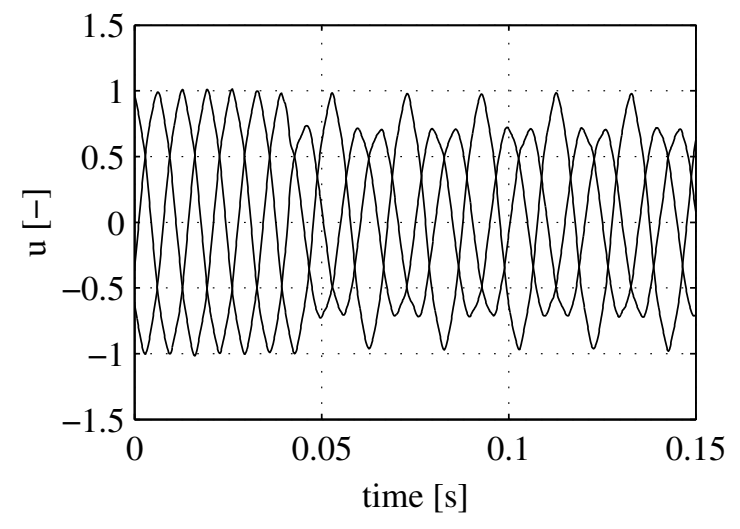

Figure 5.21: The measured main voltages of the laboratory $3 \mathrm{~kW}$ machine that correspond to an asymmetric $60 \%$ voltage dip
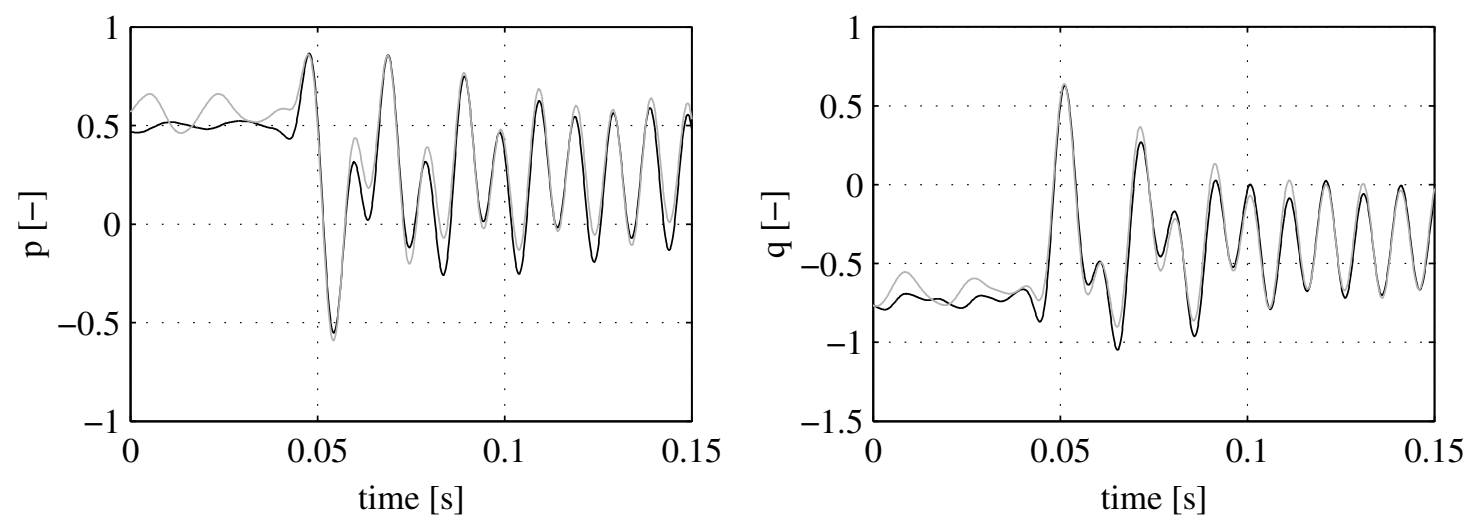

Figure 5.22: The measured (black) and simulated (gray) responses of the laboratory $3 \mathrm{~kW}$ machine to an asymmetric $60 \%$ voltage dip, active (left) and reactive (right) power 
stator magnetization appears to have a more stable generator response to voltage dips. The rotor machine magnetization, in contrast, may lower power losses. A comparison of the two machine magnetization strategies is beyond the scope of this thesis. It can, however, be interesting to observe the impact of the crow-bar action on machine behavior for machine magnetization via the rotor. Switching the crowbar causes a loss of machine magnetization that needs to be covered by the stator current. Simulation results in Fig. 5.23 show, however, that this should not impose any remarkable current increase on the machine stator side. The presented data correspond to a $20 \%$ generator load operation and a symmetric $40 \%$ dip is applied to the machine stator.
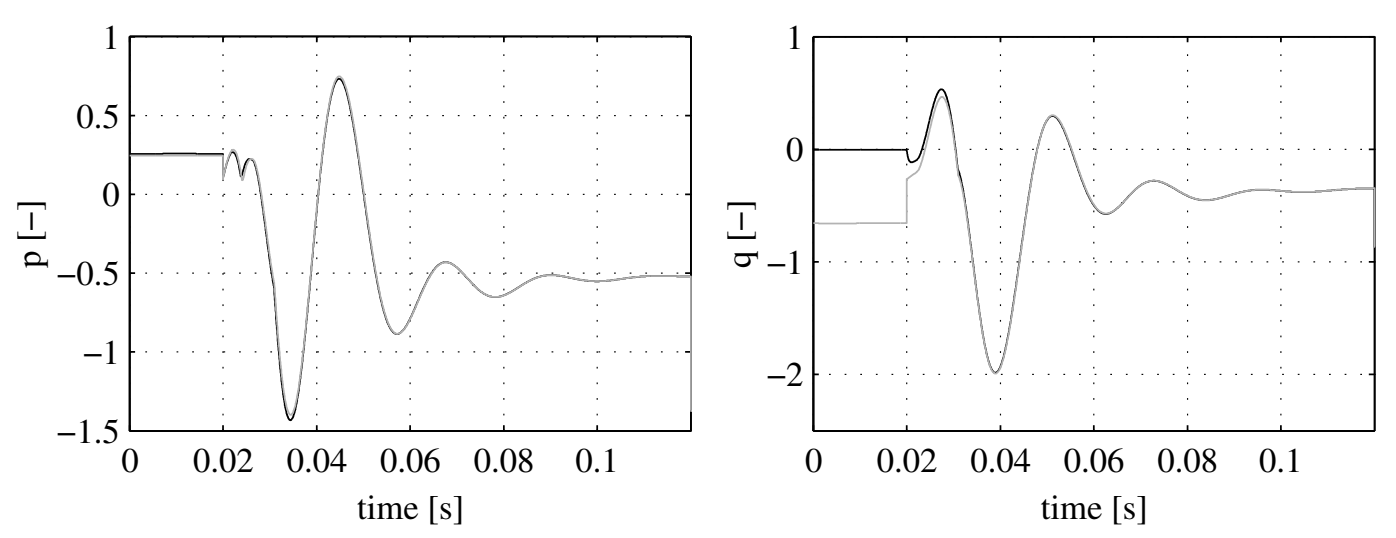

Figure 5.23: Simulated response of a doubly-fed induction machine equipped with a rotor crow-bar to a symmetric $40 \%$ voltage dip. Magnetization from rotor (black) and stator (gray) is implemented in the machine control. Stator active (left) and reactive (right) power 


\section{Chapter 6}

\section{Conclusions and Future Work}

The mutual impact of wind turbines and the grid has been measured, analyzed and modeled in this thesis. The most common wind turbine systems used today (2003) have been considered within the scope of this research project. Extensive field data has been acquired from three wind turbine sites. Apart from the identification of the mutual impact of wind turbines and the grid, the acquired data were used to draw conclusions pertaining to modeling needs for individual wind turbine types, under steady-state operation and on grid fault occasions, and for verification of the proposed models. The wind turbine models were developed in Matlab [38] programming language and, when appropriate, implemented in the grid simulation program PSS/E, Power System Simulator for Engineering [39].

\subsection{Steady State Impact}

The steady-state impact of the wind turbines, in this research restricted to the steady-state and dynamic voltage level impact, must be studied mainly for fixedspeed systems with asynchronous generators directly connected to the grid. This conclusion agrees well with results found in the literature. Variable-speed systems equipped with power electronic converters impose minor impact on the grid during steady-state operation and modeling these systems appears to be of little practical interest. Of course, there are exceptions, especially now when this technology is new.

A model of a stall-regulated, fixed-speed wind turbine system capable of predicting dynamic voltage variations in the connected electric grid has been introduced and verified against measurements. A model structure has been suggested with two different approaches for the wind simulation and aerodynamic conversion parts of the model. These approaches differ in computational requirements, a more advanced approach is not suitable for time effective modeling of the system, but this approach is used as a tool to adjust the other, less time-consuming approach. The other building blocks of the wind turbine model, the parts that represent drive-train mechanics and the generator, are common to both approaches. 
Simulations were verified against field measurements in two steps. First, the frequency spectra of the acquired and simulated results; namely the active and reactive powers, have been compared. Second, the results have been used to calculate dynamic voltage variations and, subsequently, the resulting $\mathrm{P}_{\text {st }}$ values were compared. A general conclusion is that the accuracy of the $\mathrm{P}_{\text {st }}$ prediction is better for a more inductive grid, an error up to about $5 \%$, while the prediction of the $\mathrm{P}_{\text {st }}$ values for a more resistive grid yields lower accuracy, an error up to about $25 \%$. It has been found that the quality of the supply grid voltage has a significant impact on model outcomes.

\subsection{Fault Response}

It has been found and verified by measurements that a standard induction machine model description, combined with a soft-shaft description of the drive train is a satisfactory tool for predicting the fault response behavior of fixed-speed wind turbine systems. The induction machine model with the included description of stator and rotor dynamics predicts a fast stator dynamic behavior including the $50 \mathrm{~Hz}$ oscillations. The induction machine model with neglected stator dynamics, often used in power system analysis [40], only predicts the rotor dynamic response. The fast stator dynamic behavior with $50 \mathrm{~Hz}$ oscillations that immediately follows a grid fault is not predicted by this model structure and this implies that a stator surge current following the grid fault is not predicted as well. A more complex model of the induction machine that also includes the skin effect in the rotor bars and the saturation of the leakage inductances and machine winding resistances provides no remarkable improvement of the simulated generator outcomes for the type of supply grid faults considered throughout this thesis. However, the more advanced model leads to a large increase in the computational burden and, therefore, is not recommended.

Fault response modeling of variable-speed systems is, to a considerable extent, influenced by power electronic converter behavior. For this reason, it is not possible to introduce a generally valid representation of the variable-speed system connected to the grid via a power electronic converter. Knowledge of the pre-programmed details of the power electronic converter must be available in order to produce a reasonably accurate representation of a specific wind turbine system. The behavior of the variable-speed system with a doubly-fed induction machine can be simplified while its features that are important from a power system point of view are intact. A response to less severe grid faults that can be handled by the rotor converter does not need to be described in detail and the system can be considered to be a constant power source in grid simulation programs like PSS/E [39]. The response to more severe grid disturbances that cannot be handled by the rotor converter can be covered by the use of the standard induction machine model, as in the case of the fixed-speed system, which is initiated at a given operational point. Knowledge of the control details of the grid-connected converter would, of course, increase the accuracy of the predicted response for this wind turbine model. 


\subsection{Future Work}

Since interest in predicting the response of wind turbines to grid faults is increasing and often addressed, it would be beneficial, in the author's opinion, to concentrate on the following issues in future research.

- Assessment of the power system requirements on wind turbine behavior during grid faults, based on the available operational potential of modern wind turbines would be beneficial.

- The potential, applicability and reliability of on-line communication between the power system operator and huge wind parks that would allow for direct control of the wind parks at any instance could also be subjected to further research. A corresponding change in today's installation standards that would convert wind turbines from grid -dependent and uncontrolled "troublemakers" to grid -supporting and reinforcing components could be explored in more detail.

- On-line communication with wind turbines could allow, e.g. for controlled island operation, synchronization back to the main power system without any need for supply interruptions on the customer end and utilization of the wind parks as peak sources of active and reactive power on a very short time scale. These issues could be subjected to further investigations. 


\section{Bibliography}

[1] Spera, D.A.: Wind Turbine Technology, ASME PRESS, 1994

[2] www.ewea.org, Record growth for global wind power in 2002, press release, March 3, 2003

[3] Rodriguez, J.L.A., Rodriguez, G.F., Burgos, J.C., Experimental Rig to emulate Wind Turbines, International Conference on Electric Machines, Istanbul, Turkey, September 1998

[4] Wilkie, J., Leithead, W.E., Anderson, C., Modelling of Wind turbines by Simple Models, Wind Engineering, Vol. 13, No. 4, 1990

[5] Bossanyi, E.A., Gardner, P., Craig, L., Saad-Saoud, Z., Jenkins, N., Miller, J., Design Tool for prediction of flicker, European Wind Energy Conference, Dublin Castle, Ireland, 1997

[6] Akhmatov, V., Knudsen, H., Nielsen, A.H., Advanced simulation of windmills in the electrical power supply, International Journal of Electrical Power and Energy Systems, July 2002, Vol.22, No. 6, p. 421 - 434

[7] Leithead, W.E., Rogers, M.C.M., Drive-train Characteristics of Constant Speed HAWT's: Part I - Representation by Simple Dynamics Models, Wind Engineering, Vol. 20, No. 3, 1996

[8] Leithead, W.E., Rogers, M.C.M., Drive-train Characteristics of Constant Speed HAWT's: Part II - Simple Characterisation of Dynamics, Wind Engineering, Vol. 20, No. 3, 1996

[9] Bao, N.Sh., Chen, Q.X., Jiang, T., Modelling and Identification of a Wind Turbine System, Wind Engineering, Vol. 20, No. 4, 1996

[10] Jenkins, N., Saad-Saoud, Z., A simplified model for large wind turbines, European Union Wind Energy Conference, Göteborg, Sweden, 1996

[11] Usaola, J., Vilar, C., Amaris, P., Ledesma, P., Rodriguez, J.L., Characterization of WECS through power spectra for power quality studies, European Wind Energy Conference (EWEC '99), Nice, France, Mars 1-5, 1999

[12] Thiringer, T., Measurements and Modelling of Low-Frequency Disturbances in Induction Machines, Ph.D. thesis, Chalmers University of Technology, 1996, ISBN 91-7197-384-2 
[13] Larsson, A., Sørensen, P., Santjer, F., Grid Impact of Variable-Speed Wind Turbines, European Wind Energy Conference (EWEC '99), Nice, France, Mars 1-5, 1999, Proceedings, p.786-789

[14] Lundberg S., Electrical limiting factors for wind energy installations, Diploma thesis, Chalmers University of Technology, 2000, ISSN 1401-6184

[15] Rodríguez, J.M., Fernández, J.L., Beato, D., Iturbe, R., Usaola, J., Ledesma, P., Wilhelmi, J.R., Incidence on Power System Dynamics of High Penetration of Fixed Speed and Doubly Fed Wind Energy Systems: Study of the Spanish Case, IEEE Transactions on Power Systems, Vol. 17, No. 4, November 2002, p. $1089-1095$

[16] Hansen, L.H., Helle, L., Blaabjerg, F., Ritchie, E., Munk-Nielsen, S., Bindner, H., Sørensen, P., Bak-Jensen, B., Conceptual survey of Generators and Power Electronics for Wind Turbines, Ris $\varnothing$ National Laboratory, Roskilde, Denmark, 2001

[17] www.vestas.com, Vestas V47-660kW brochure

[18] Grauers, A., Design of Direct-driven Permanent-magnet Generators for Wind Turbines, Ph.D. thesis, Chalmers University of Technology, 1996, ISBN 917197-373-7

[19] Anslutning av Mindre Produktionsanläggningar till elnätet (AMP), Sveriges elleverantörer, 1999, (in Swedish)

[20] International Electrotechnical Commission, IEC 61400-21, Ed.1: Wind turbine generator systems - Part 21: Measurements and assessment of power quality characteristics of grid connected wind trubines, December 2001

[21] Larsson, A., The Power Quality of Wind Turbines, Ph.D. thesis, Chalmers University of Technology, 2000, ISBN 91-7197-970-0

[22] Bollen M.H.J., Ongoing Standard Work on Statistical Presentation of Voltage Dips, PMAPS 2002, Proceedings of 7th International Conference on Probabilistic Methods Applided to Power Systems, Naples, Italy, September 22-26, 2002, p. $575-580$

[23] Larsson, A., Thiringer, T., Measurements on and Modelling of CapacitorConnecting Transients on a Low-voltage Grid equipped with Two Wind Turbines, International Conference on Power System Transients (IPST'95), Lisbon, Portugal, September 3-7, 1995, proceedings p.184-188

[24] International Electrotechnical Commission, IEC 61000-4-15, Flickermeter Functional and design specifications (11/1997)

[25] www.vestas.com, Vestas V52-850kW brochure

[26] International Electrotechnical Commission, IEC 61000-4-7, Electromagnetic Compatibility, General Guide on Harmonics and Inter-harmonics Measurements and Instrumentation, 1991 
[27] Petersson, A., Analysis, Modeling and Control of Doubly-Fed Induction Generators for Wind Turbines, Licentiate thesis, Chalmers University of Technology, 2003, ISSN 1651-4998

[28] Winkelaar, D., Fast three dimensional wind simulation and the prediction of stochastic blade loads, 10th ASME Wind Energy Symposium, ASME, 1991

[29] Freris, L.L., Wind Energy Conversion Systems, Prentice Hall International (UK) Ltd, 1990

[30] Eggleston, D. M., Stoddard, F.S., Wind Turbine Engineering Design, ISBN 0-442-22195-9

[31] Persson, E., One-dimensional wind simulation, Studies in statistical quality, control and reliability 1996:2, ISBN 992-273382-x

[32] Kovacs, P.K., Transient phenomena in electrical machines, Elsevier, Budapest, 1984

[33] Rodriguez, F.D., A refined method of neglecting stator transients in induction loads, Ph.D. thesis, Purdue University, 1986

[34] Carlson, O., Analysis of synchronous generator with frequency convertor for electrical power generation with variable speed, Ph.D. thesis, Chalmers University of Technology, 1988, ISBN 91-7032-376-3, (in Swedish)

[35] Helmer, M., Thiringer, T., An Improved Model of Induction Machines for Accurate Predictions of Wind Generator Line Short Circuit Currents, 10th European Conference on Power Electronics and Applications (EPE 2003), Toulouse, France, September 2-4, 2003

[36] Slemon, G.R., Modelling of Induction Machines for Electric Drives, IEEE Transactions on Industry Applications, Vol. 25, No. 6, November/December 1989

[37] Harnefors, L., Nee H.P., Control of Variable-Speed Drives, Royal Institute of Technology, Stockholm, Sweden, 2000

[38] www.mathworks.com, Matlab ${ }^{\circledR}$ - the language of technical computing, The MathWorks, Inc

[39] www.pti-us.com, Power System Simulator for Engineering, Power Technologies, $\mathrm{INC}^{\mathrm{R}}$

[40] Kundur, P., Power System Stability and Control, McGraw-Hill, 1994, ISBN 0-07-035958-X 


\title{
Nomenclature
}

\author{
Abbreviations \\ ASR active-stall regulated turbine \\ DAQ data acquisition \\ DC direct current \\ DFIG doubly fed induction generator \\ EMF electro motive force \\ FSS fixed-speed system \\ IM induction machine \\ PEC power electronic converter \\ PR pitch-regulated turbine \\ PWM pulse width modulation \\ SR stall-regulated turbine \\ VSS variable-speed system \\ WT wind turbine
}

\section{Terms}

$\alpha \quad$ angle of attack

$\alpha_{e} \quad$ current control closed-loop system bandwidth

$\gamma \quad \Gamma$-model representation scaling constant

$\vartheta \quad$ angle of generator shaft

$\lambda \quad$ tip speed ratio

$\Psi_{r} \quad$ rotor magnetic flux referred to the stator side

$\Psi_{R} \quad$ rotor magnetic flux of the $\Gamma$-model representation

$\Psi_{s} \quad$ stator magnetic flux

$\omega_{r} \quad$ generator rotor angular speed (referred to the electrical system)

$\omega_{1} \quad$ synchronous frequency

$\omega_{2} \quad$ slip frequency

$\Omega \quad$ turbine angular speed (low speed shaft)

$C_{p} \quad$ turbine power coefficient

$c\left(\Psi_{k}\right) \quad$ turbine flicker coefficient

d turbine rotor diameter

f frequency

i, I current

$i_{r} \quad$ rotor current referred to the stator side 
$i_{R} \quad$ rotor current of the $\Gamma$-model representation

$i_{s} \quad$ stator current

$J \quad$ generator moment of inertia

$k_{a b} \quad$ scaling constant of the state-space vector transformation

$k_{i} \quad$ integral gain

$k_{p} \quad$ proportional gain

$L_{\sigma} \quad$ leakage inductance of the $\Gamma$-model representation

$L_{m} \quad$ magnetizing inductance

$L_{M} \quad$ magnetizing inductance of the $\Gamma$-model representation

$L_{r l} \quad$ rotor leakage inductance referred to the stator side

$L_{s l} \quad$ stator leakage inductance

$M \quad$ mutual inductance

n generator speed

$n_{p} \quad$ number of pole pairs

$\mathrm{p}, \mathrm{P} \quad$ active power

$P_{g} \quad$ grid active power

$P_{m} \quad$ mechanic power

$P_{r} \quad$ rotor active power

$P_{s} \quad$ stator active power

$P_{s t} \quad$ short time flicker severity index

q, Q reactive power

$\mathrm{r} 1, \mathrm{r} 2, \mathrm{r} 3$ rotor three phase system

$\mathrm{R} \quad$ turbine radius

$R_{a} \quad$ active damping resistance

$R_{r} \quad$ rotor winding resistance referred to the stator side

$R_{R} \quad$ rotor winding resistance of the $\Gamma$-model representation

$R_{s} \quad$ stator winding resistance

s1, s2, s3 stator three phase system

$T_{\text {elmg }} \quad$ electromagnetic torque

$T_{l} \quad$ load torque

$T_{s 1} \quad$ torque contribution due to one stator phase

$\mathrm{THD}_{u} \quad$ voltage total harmonic distortion

$\mathrm{THD}_{i} \quad$ current total harmonic distortion

$\mathrm{u}, \mathrm{U} \quad$ voltage

$u_{r} \quad$ rotor voltage referred to the stator side

$u_{R} \quad$ rotor voltage of the $\Gamma$-model representation

$u_{s} \quad$ stator voltage

W wind speed acting on a blade

WS free wind speed 
Publication 1

Wind power stations - the impact on the electric grid, basic configurations and an example of utilisation

Petru, T., The conference on Electric Power Engineering ELEN2000, Prague, Czech Republic, 25.-26.9.2000 


\section{Publication 2}

Power quality impact of a sea-located hybrid wind park

Thiringer, T., Petru, T., Liljegren, C., IEEE Transactions on Energy Conversion, vol. 16, no. 2, June 2001, p. 123-127 


\section{Publication 3}

Integration of wind parks - example from Bockstigen

Petru, T., Thiringer, T., Nordic Wind Power Conference NWPC'2000, Trondheim, Norway, 13.-14.3. 2000 
Publication 4

Active flicker reduction from a sea-based 2.5 MW wind park connected to a weak grid

Petru, T., Thiringer, T., 2000 IEEE Nordic Workshop on Power and Industrial Electronics NORpie/2000, Aalborg, Denmark, 13.-16.6.2000 
Publication 5

Measurement and modeling of power quality impact of a stall-regulated wind turbine

Petru, T., Thiringer, T., Electromotion journal, vol. 8, no. 2, April - June 2001, p. 104-110 
Publication 6

Flicker contribution from wind turbine installations

Thiringer, T., Petru, T., Lundberg, S., accepted for publication in IEEE transactions on Energy conversion 


\section{Publication 7}

Electrical Limiting Factors for Wind Energy Installations in Weak Grids

Lundberg, S., Petru, T., Thiringer, T., International Journal of Renewable Energy Engineering, vol. 3, no. 2, August 2001, p. 305-310 


\section{Publication 8}

Modeling of wind turbines for power system studies

Petru, T., Thiringer, T., IEEE Transactions on Power Systems, vol. 17, no. 4, November 2002, p. 1132-1139 
Publication 9

Grid Disturbance Response of Wind Turbines Equipped with Induction Generator and Doubly-Fed Induction Generator

Thiringer, T., Petersson, A., Petru, T., accepted for IEEE PES Annual Meeting, Toronto, Canada, July 2003 